\title{
Outline of the Fukushima Daiichi Accident. Lessons Learned and Safety Enhancements
}

\author{
Masashi Hirano* \\ Nuclear Regulation Authority, Japan
}

\begin{abstract}
On March 11, 2011, an earthquake and subsequent tsunamis off the Pacific coastline of Japan's Tohoku region caused widespread devastation in Japan. As of June 10, 2016, it is reported that a total of 15,894 people lost their lives and 2,558 people are still unaccounted for. In Fukushima Prefecture, approximately 100,000 people are still obliged to live away from their homes due to the earthquake and tsunami as well as the Fukushima Daiichi accident.
\end{abstract}

On the day, the earthquake and tsunami caused severe damages to the Tokyo Electric Power Company (TEPCO)'s Fukushima Daiichi Nuclear Power Station (NPS). All the units in operation, namely Units 1 to 3 , were automatically shut down on seismic reactor protection system trips but the earthquake led to the loss of all off-site electrical power supplies to that site. The subsequent tsunami inundated the site up to 4 to $5 \mathrm{~m}$ above its ground level and caused, in the end, the loss of core cooling function in Units 1 to 3, resulting in severe core damages and containment vessel failures in these three units. Hydrogen was released from the containment vessels, leading to explosions in the reactor buildings of Units 1, 3 and 4. Radioactive materials were released to the atmosphere and were deposited on the land and in the ocean.

\begin{abstract}
One of the most important lessons learned is an importance to prevent such large scale common cause failures due to extreme natural events. This leads to a conclusion that application of the defense-in-depth philosophy be enhanced because the defense-in-depth philosophy has been and continues to be an effective way to account for uncertainties associated with risks. From the human and organizational viewpoints, the final report from the Investigation Committee of the Government pointed out so-called "safety myth" that existed among nuclear operators including TEPCO as well as the government, that serious severe accidents could never occur in nuclear power plants in Japan.
\end{abstract}

After the accident, the Nuclear Regulation Authority (NRA) was established on September 19, 2012. The NRA very urgently developed and issued the new regulatory requirements on July 8, 2014, taking into the account the lessons learned from the accident. It is noted that the NRA issued the Statement of Nuclear Safety Culture on May 27, 2015 which clearly expressed the NRA's commitment to break with the safety myth.

This paper briefly presents the outline of the Fukushima Daiichi accident and summarizes the major lessons learned having been drawn and safety enhancements having been done in Japan for the purpose of giving inputs to the discussions to be taken place in the Special Invited Session "Fukushima, 5 years after".

\footnotetext{
${ }^{*}$ Corresponding author: masashi.hirano@,nsr.go.jp
} 


\section{Fukushima Special Session \\ "Fukushima, 5 years after"}

\section{Outline of the Fukushima Daiichi Accident, Lessons Learned and Safety Enhancements}

\section{Masashi HIRANO and Harutaka HOSHI Nuclear Regulation Authority (NRA)}

\section{The joint conference of}

the $13^{\text {th }}$ Int. Conf. on Radiation Shielding (ICRS-13), and $19^{\text {th }}$ Topical Meeting of the Radiation Protection and Shielding Division of ANS - 2016 (RPSD-2016) 


\section{Contents}

- Introduction

- Current Status of Nuclear Regulation in Japan

- Outline of the Accident

- Earthquake and Tsunami

- Accident Progression

- Source Term Evaluation

- Lessons Learned

- Safety Enhancements

- Creation of NRA

- New Regulatory Requirements

- Summary 


\section{Current Status of Nuclear Regulation in Japan}

- NRA was established in Sep. 2012 and developed the new regulatory requirements for NPPs which came into force in July 2013.

- All the 48 units had been shut down since Sep. 2013.

- So far, a total of 26 units (17 PWRs and 9 BWRs) have applied for conformance review.

- In Sep. 2014, NRA first approved the applications from Sendai Units 1 and 2.

- As of Aug. 2016, NRA has granted permission to 7 PWRs of which four units have restarted (Sendai Units 1,2 and Takahama Units 3, 4)

- The IAEA IRRS mission's review was taken place in Jan. 2016.

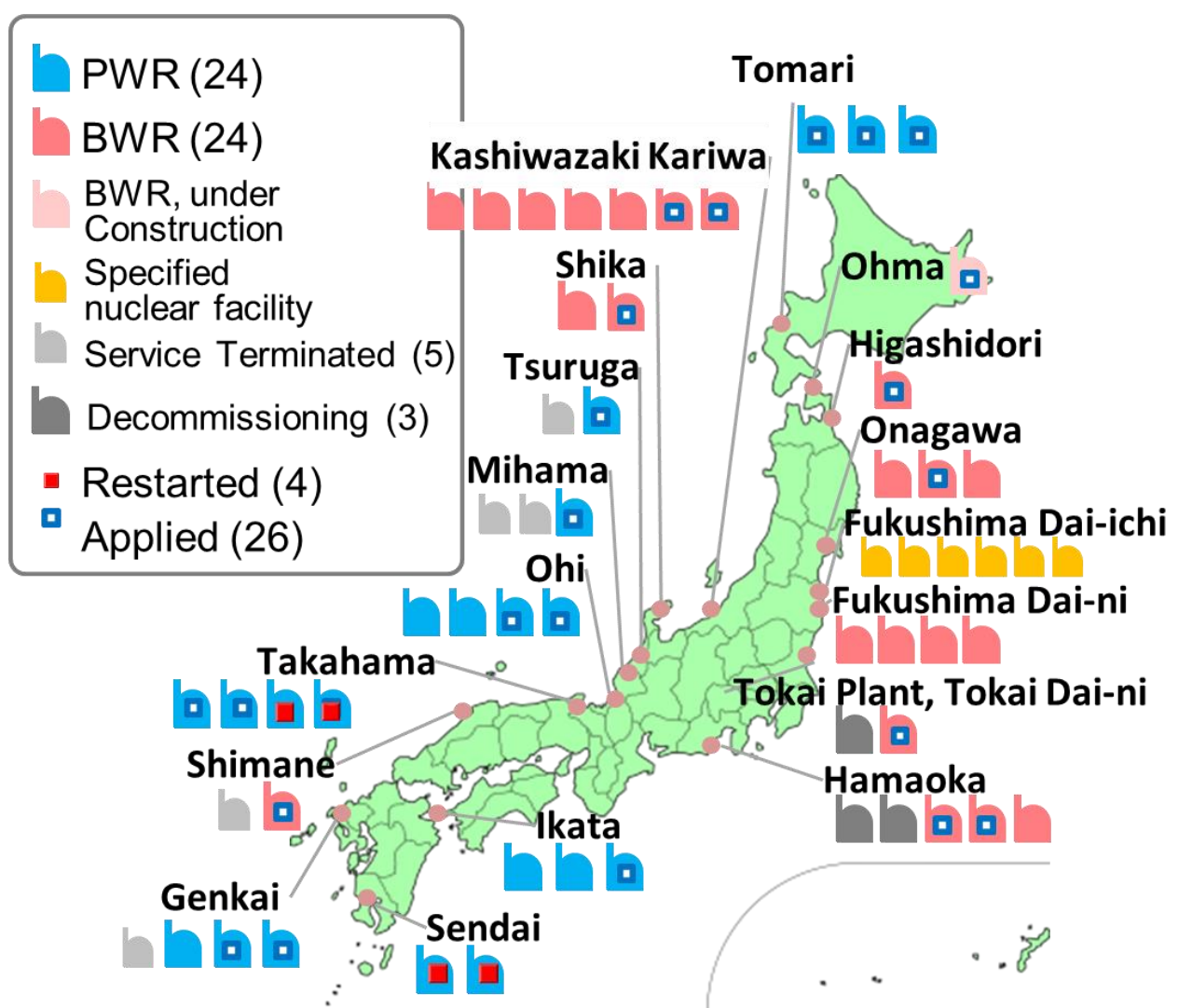




\section{Outline of the Accident}




\section{the Pacific Ocean Earthquake}

- Occurred at 14:46 on March 11, 2011

- 9.0 Mw: largest ever recorded in Japan

- Rupture duration: $170 \mathrm{sec}$

- Epicenter: $38^{\circ} 10^{\prime \prime} \mathrm{N}$ and $142^{\circ} 86^{\prime \prime} \mathrm{E}$, $23.7 \mathrm{~km}$ in depth

- Reverse fault type near the Japan Trench North America Source area of

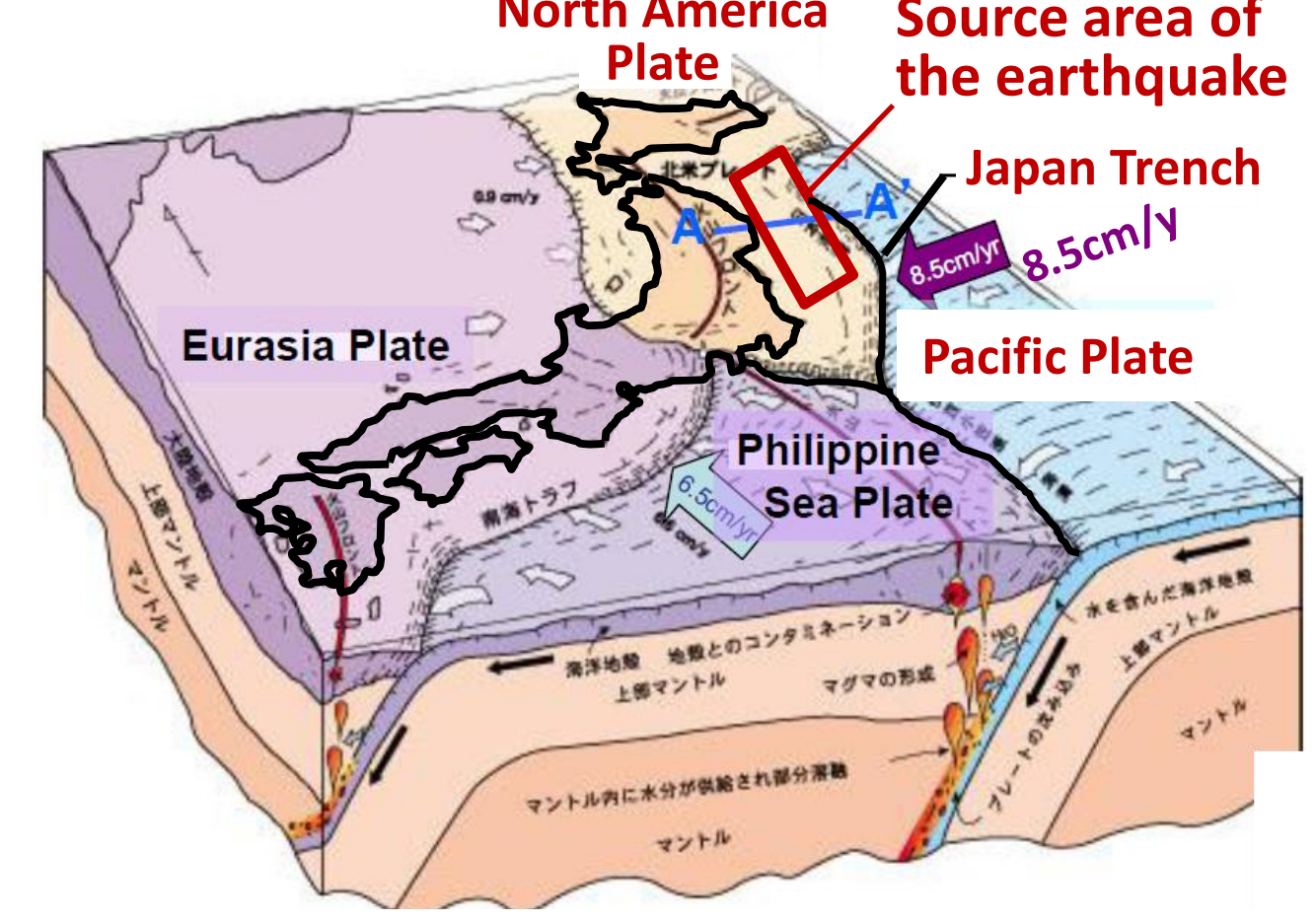

Edited to figure in " $1^{\text {st }}$ Government Report (June) 2011)"

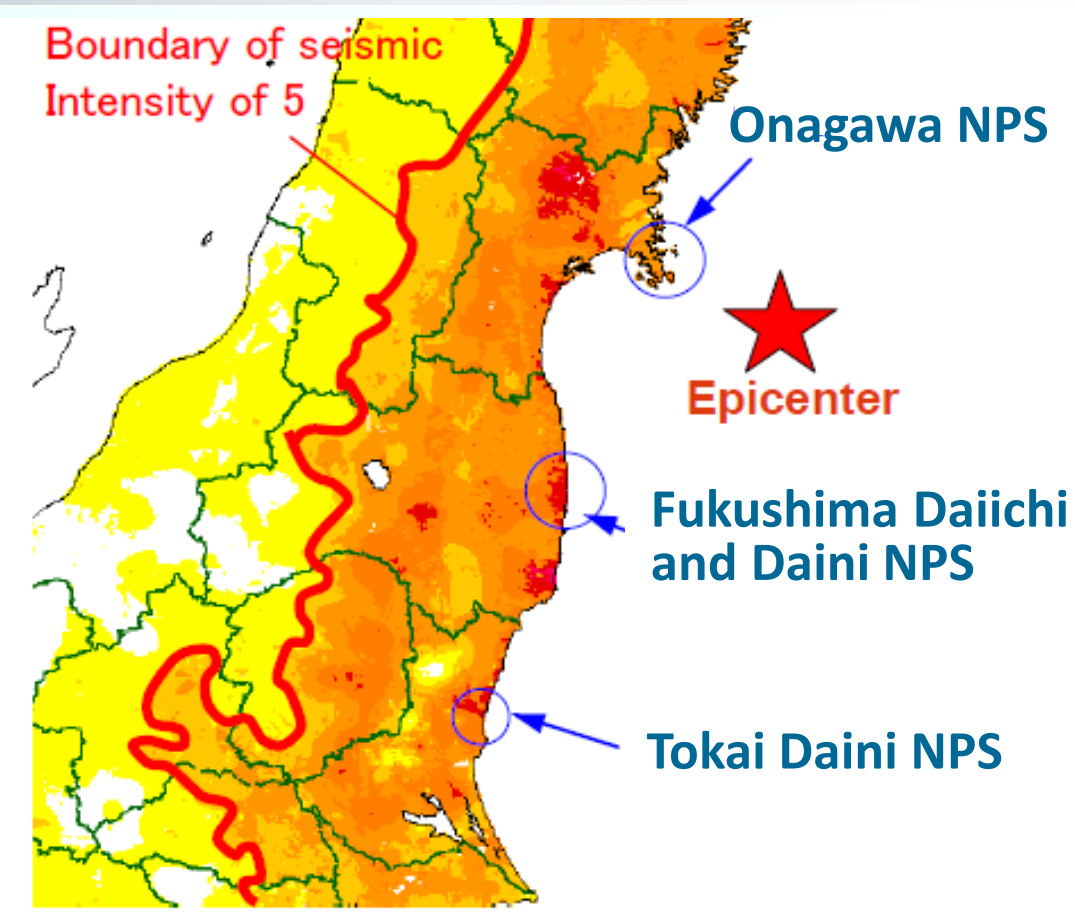

Seismic $\square \square \square \square \square($ (JMA 1st Rep.)

Intensity 4 5- 5+ 6- 6+ 7

Reference: JMA Release [Online]. http://www.jma.go.jp/jma/index.html Partially modified by JNES.

- Observed max. acceleration of seismic ground motion at Fukushima-Daiichi exceeded that of the design basis by $26 \%$. 


\section{Accompanied Tsunami}

- A huge tsunami was generated due to a large slip, more than $56 \mathrm{~m}$, near the Japan Trench.

Estimated slip distribution

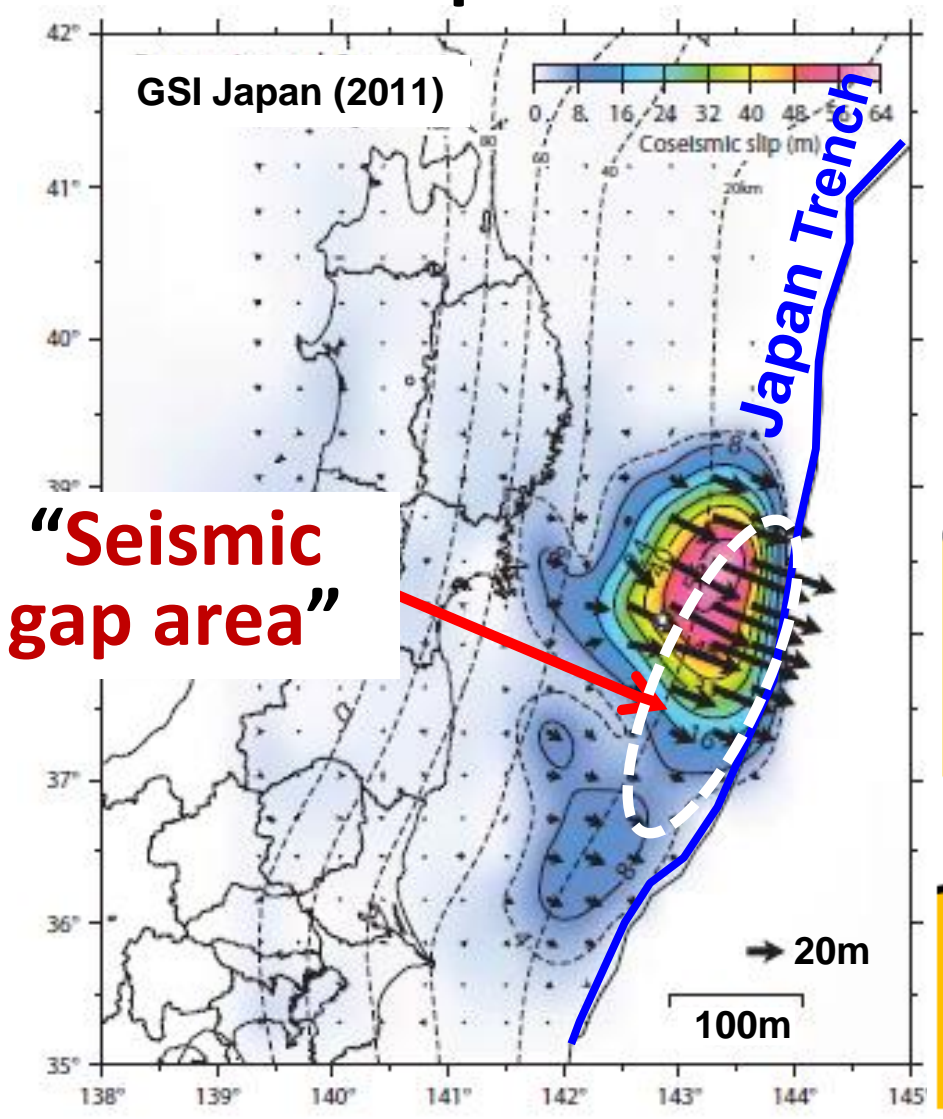

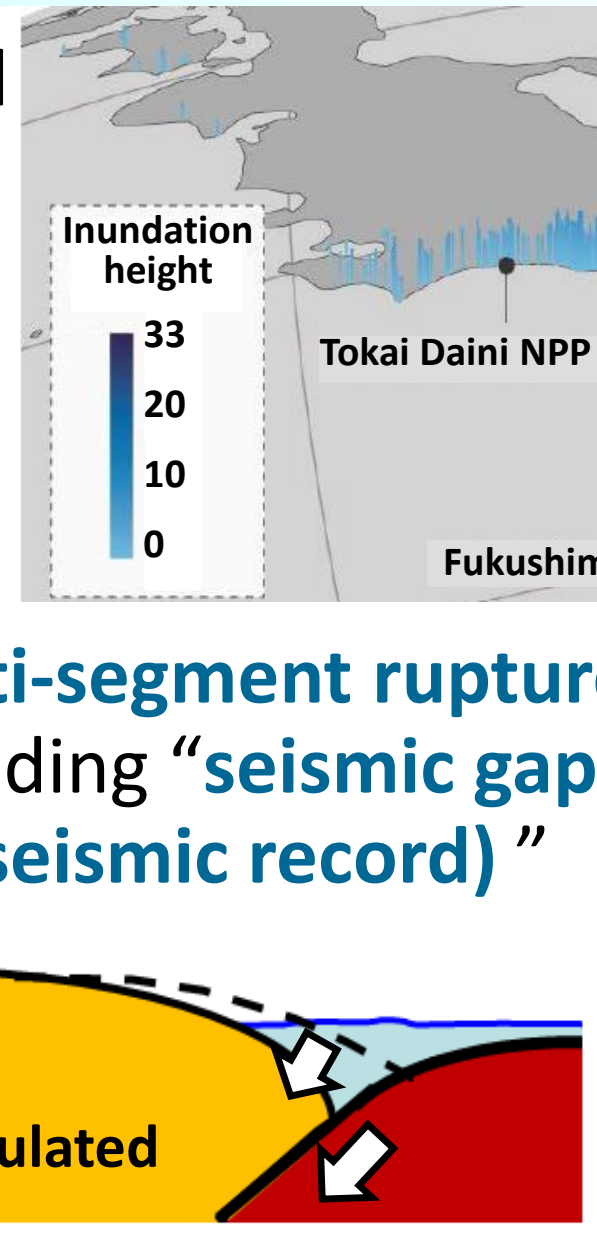

tsunami

Recoil generateed tsunami
- Due to rupture of the bonded interface, the North America Plate recoiled and the strain energy was released, which generated the huge tsunami.

Sugino, et al., NRA, 24 Feb, 2016 
and the Accident

Casualties due to earthquake/tsunami (as of Dec.1, 2011)

- Deceased: 15,840

- Injured: 5,951
- Unaccounted for: 3,547

- Damaged buildings: 1,009,074

- As of June 2016, the number of evacuees has been reduced from 470,000 to 155,000 . Still 51,000 people live in temporary housing.

- In Fukushima Prefecture, approx. 100,000 people are still obliged to live away from their homes due to the earthquake/tsunami as well as the Fukushima Daiichi accident. (website of the Fukushima Prefecture)

- Evacuation order: (1) Return is difficult (red), (2) Habitation is restricted (yellow), (3) Preparing for lifting orders (Green)

- Yellow and Green areas will be lifted no later than March 2017.

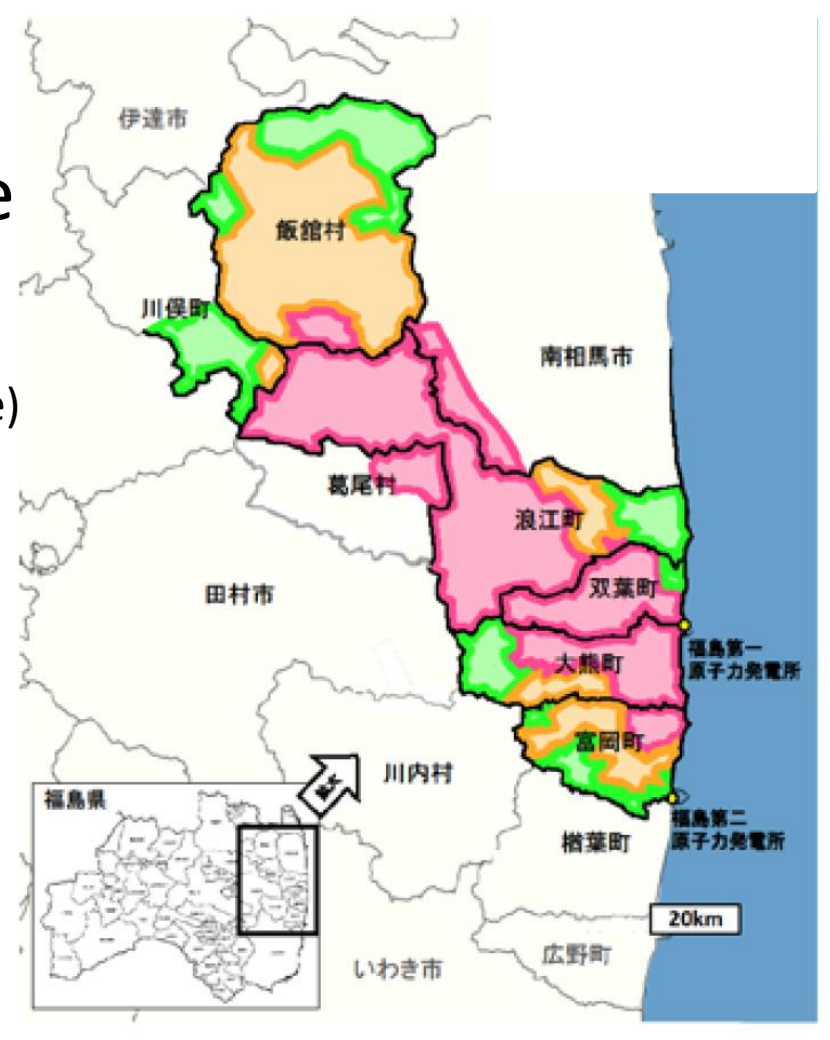




\section{Tsunami Heights at four Different Sites}

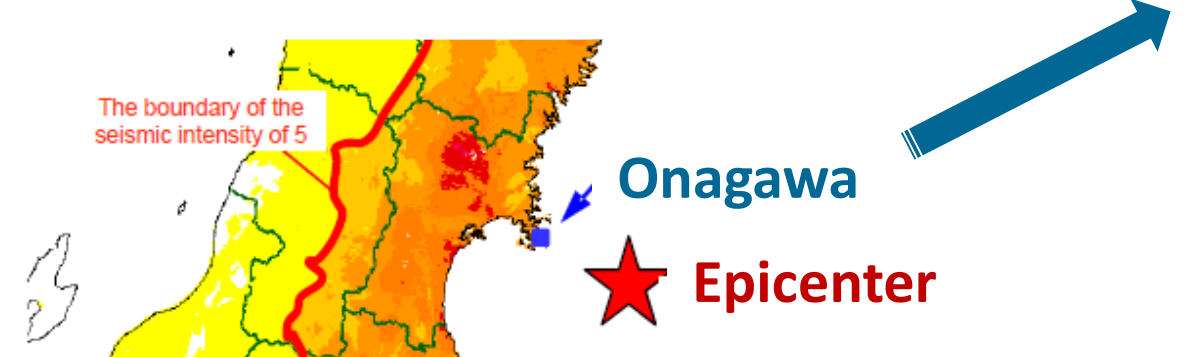

Fukushima

1 - Dai-ichi

Fukushima Dai-ni

Tokai Dai-ni
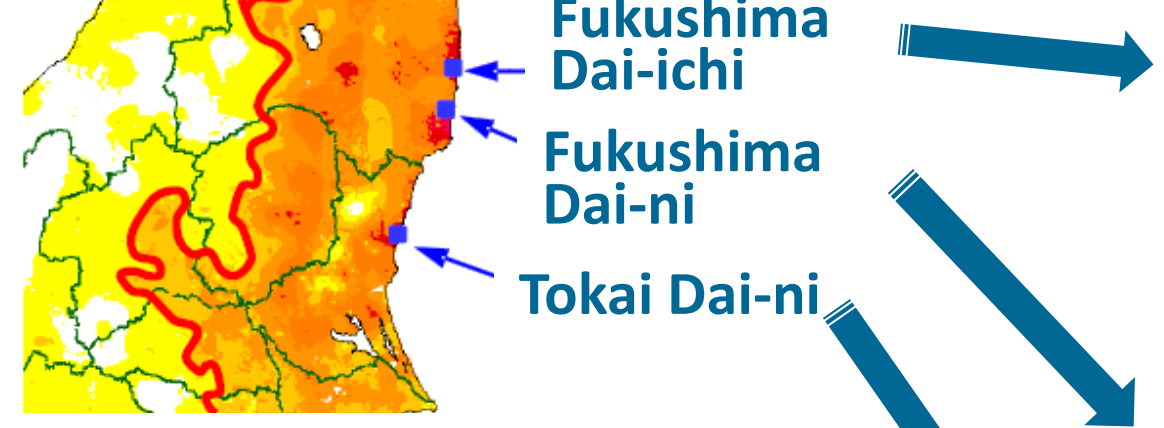

Seawall height: $10 \mathrm{~m}$

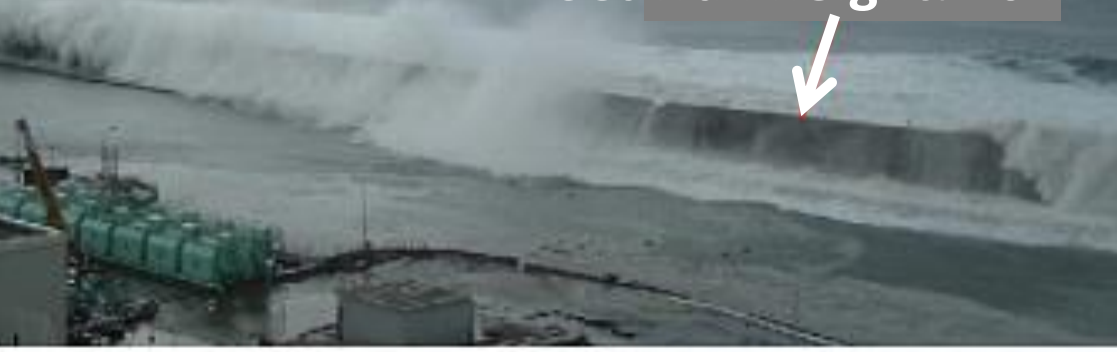

Tsunami at Fukushima Daiiichi NPS
Onagawa: Not flooded

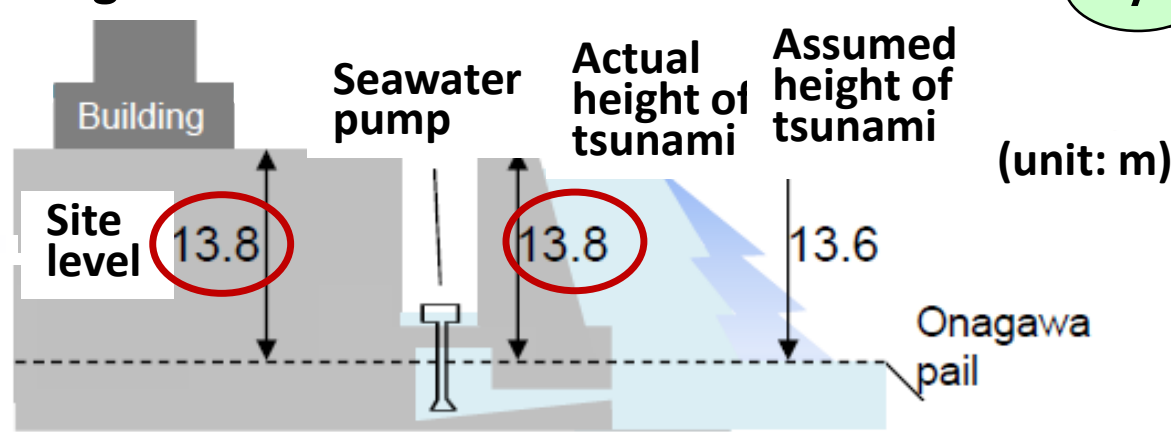

Fukushima Daiichi: Flooded destructively

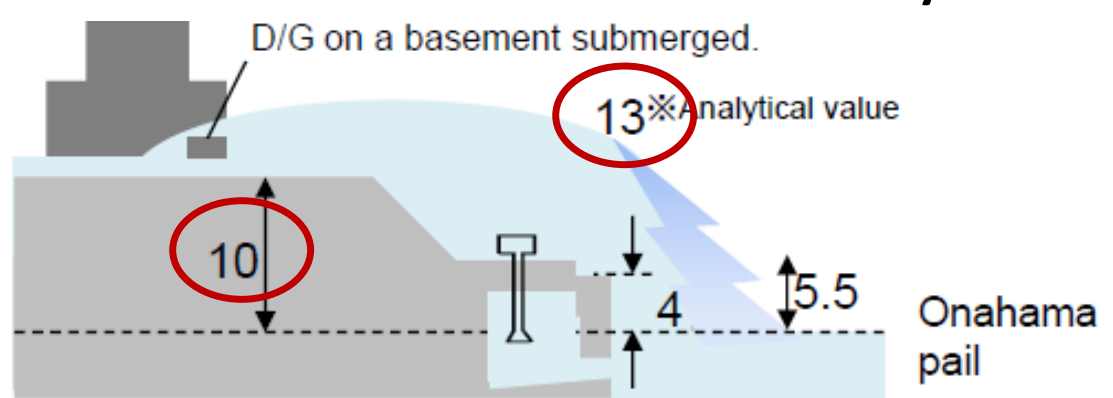

Fukushima Daini: Seawater pumps were flooded. Buildings were damaged slightly.

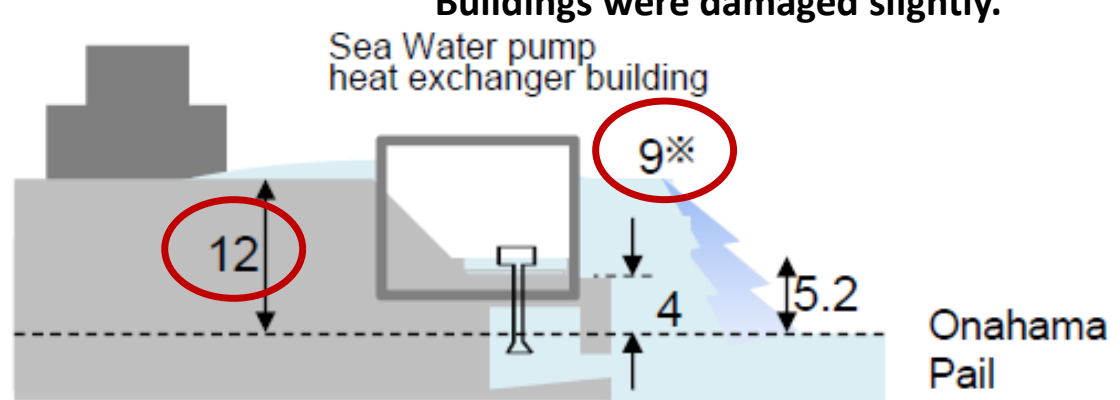

Tokai Daini: Seawater pumps were not flooded due to breakwater wall.

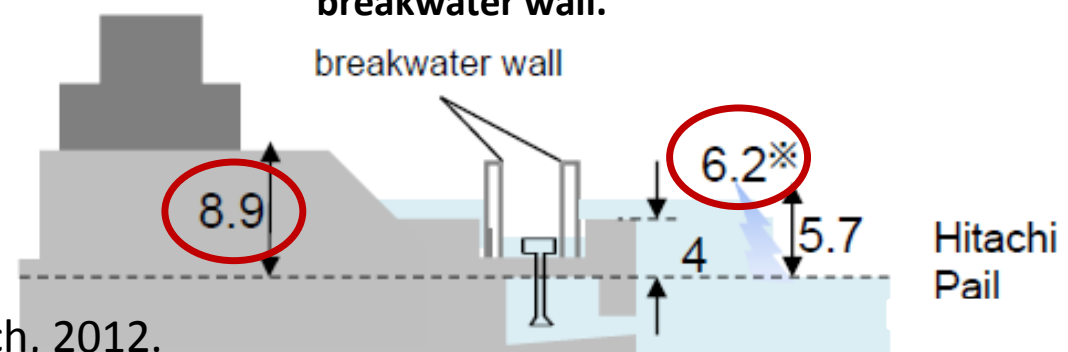




\section{Common-Cause Failures by Tsunami}

- Units 1 to 3 automatically scrammed on seismic reactor protection trips. The earthquake led to loss of offsite power. All the emergency diesel generators (EDGs) automatically started.

- Then, about $\mathbf{4 0} \mathrm{min}$. later, the tsunami arrived at the site.

- In Units 1 to 4, all the EDGs became inoperable (SBO) together with loss of DC power.* It also caused LUHS as well.

- In Unites 5 and 6, an air-cooled EDG of Unit 6 survived and it supplied AC power to both units.

*DC power was available in Unit 3.

Seawater pumps for residual heat removal became inoperable Loss of Ultimate Heat Sink (LUHS)

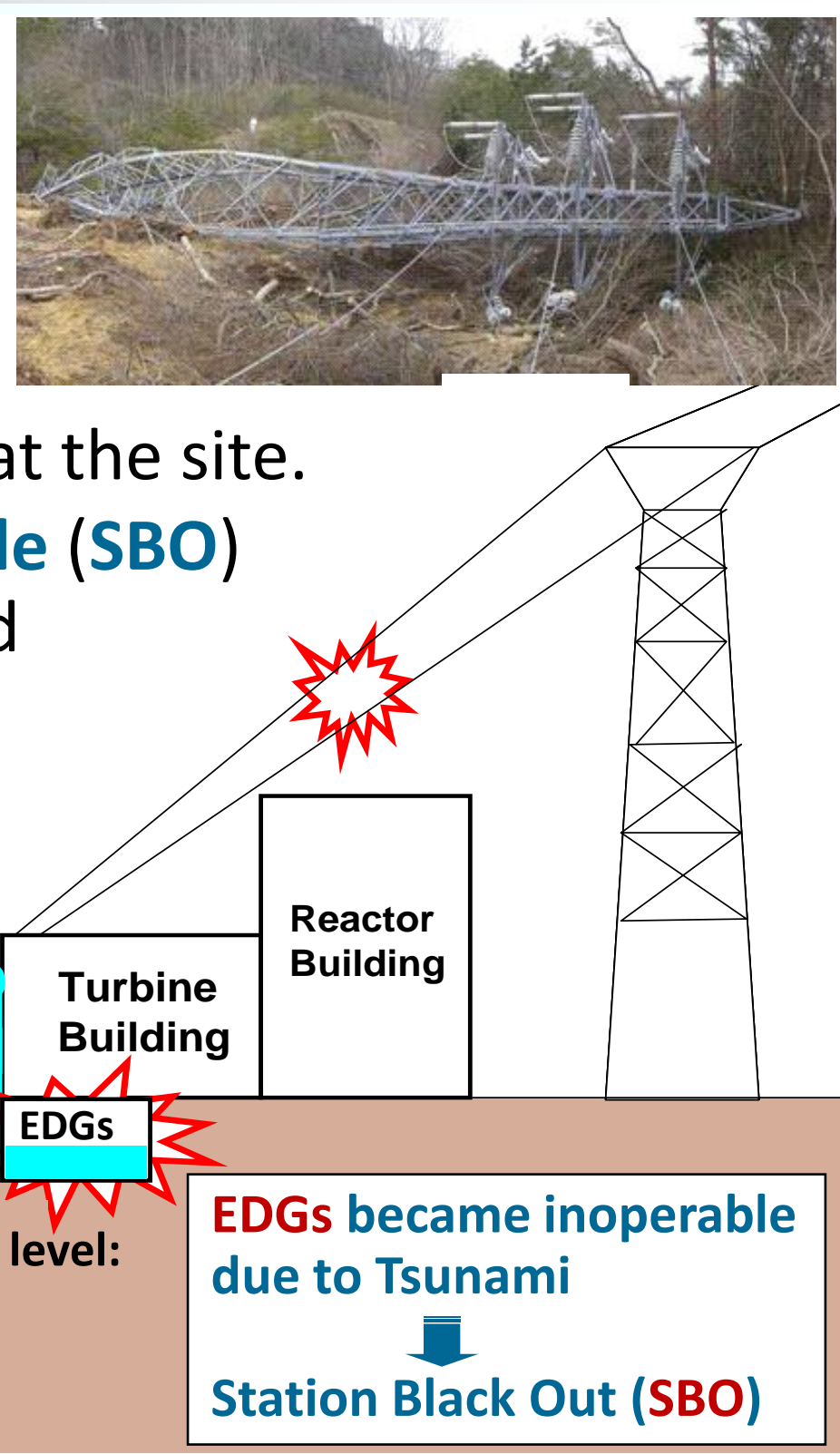




\begin{tabular}{|c|c|c|}
\hline Unit 1 & Unit 2 & Unit 3 \\
\hline \multicolumn{3}{|c|}{ 14:46 on Mar. 11: Shutdown due to earthquake } \\
\hline \multicolumn{3}{|c|}{ LOOP: Loss of off-site power $\|$ EDGs started automatically } \\
\hline $\begin{array}{l}\text { ICs (Isolation Condensers) } \\
\text { operated manually }\end{array}$ & $\begin{array}{l}\text { RCIC (Reactor Core Isolation Cooling } \\
\text { System) started manually }\end{array}$ & RCIC started manually \\
\hline \multicolumn{3}{|c|}{ 15:27 on Mar. 11: Tsunami arrived } \\
\hline \multicolumn{2}{|c|}{ Loss of AC and DC power } & Loss of $A C$ power (DC power available) \\
\hline $\begin{array}{l}\text { ICS and } \mathrm{HPCl} \text { were not operable } \\
\text { March } 12 \\
\text { - PCV venting at about 14:30 } \\
\text { - Hydrogen explosion at 15:36 } \\
\text { - Seawater injection at 19:04 }\end{array}$ & $\begin{array}{l}\text { RCIC operated for about } \\
70 \text { hours without DC power } \\
\text { March } 14 \\
\text { - RCIC stopped until 12: } 30 \\
\text { - Operators opened SRV at 18:02 } \\
\text { - Seawater injection at 19:54 } \\
\text { March } 15 \\
\text { - Possible PCV failure }\end{array}$ & $\begin{array}{l}\text { March } 12 \\
\text { - } \mathrm{RCIC} \text { stopped (11:36) and } \\
\mathrm{HPCl} \text { started (12:35) } \\
\text { March } 13 \\
\text { - } \mathrm{HPCl} \text { was shut down remote- } \\
\text { manually from MCR at 2:42 } \\
\text { - SRVs opened at 9:08 (ADS } \\
\text { conditions met). } \\
\text { - Fresh water injection at 9:25 } \\
\text { March } 14 \\
\text { - Hydrogen explosion at 11:01 }\end{array}$ \\
\hline
\end{tabular}




\section{Hydrogen Explosion at Units 1, 3}

- Hydrogen leaked from RPV to PCV and then to the $\mathrm{RB}$, and exploded there.

- Analyses were done by the former JNES with FLUENT and AUTODYN.

- It was assumed that hydrogen leaked at:

- Top flange gasket at Unit 1

- Sealing of hatch or penetrations at $1^{\text {st }}$ floor at Unit 3

$[\mathrm{kPa}]$

$1.500 \mathrm{e}+103$

$1.375 e+03$

$1.250 \mathrm{e}+103$

$1.125 e+03$

$1.000 \mathrm{e}+03$

$8.750 e+02$

$7.500 \mathrm{e}+02$

$6.250 e+02$

$5.000 \mathrm{e}+02$

$3.750 e+02$

$2.500 \mathrm{e}+02$

$1.250 e+02$

$0.000 e+00$

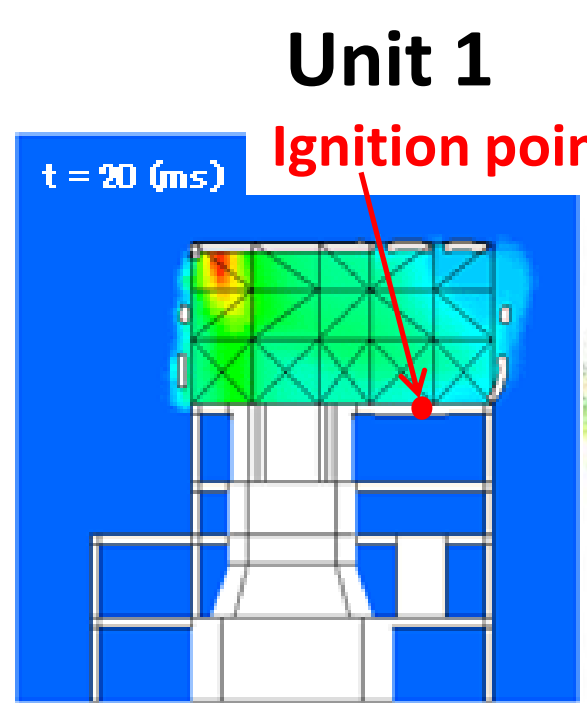

Pressure $(t=20 \mathrm{~ms})$
https://en.wikipedia.org/wiki/File:Browns_Ferry_Un it_1_under_construction.jpg
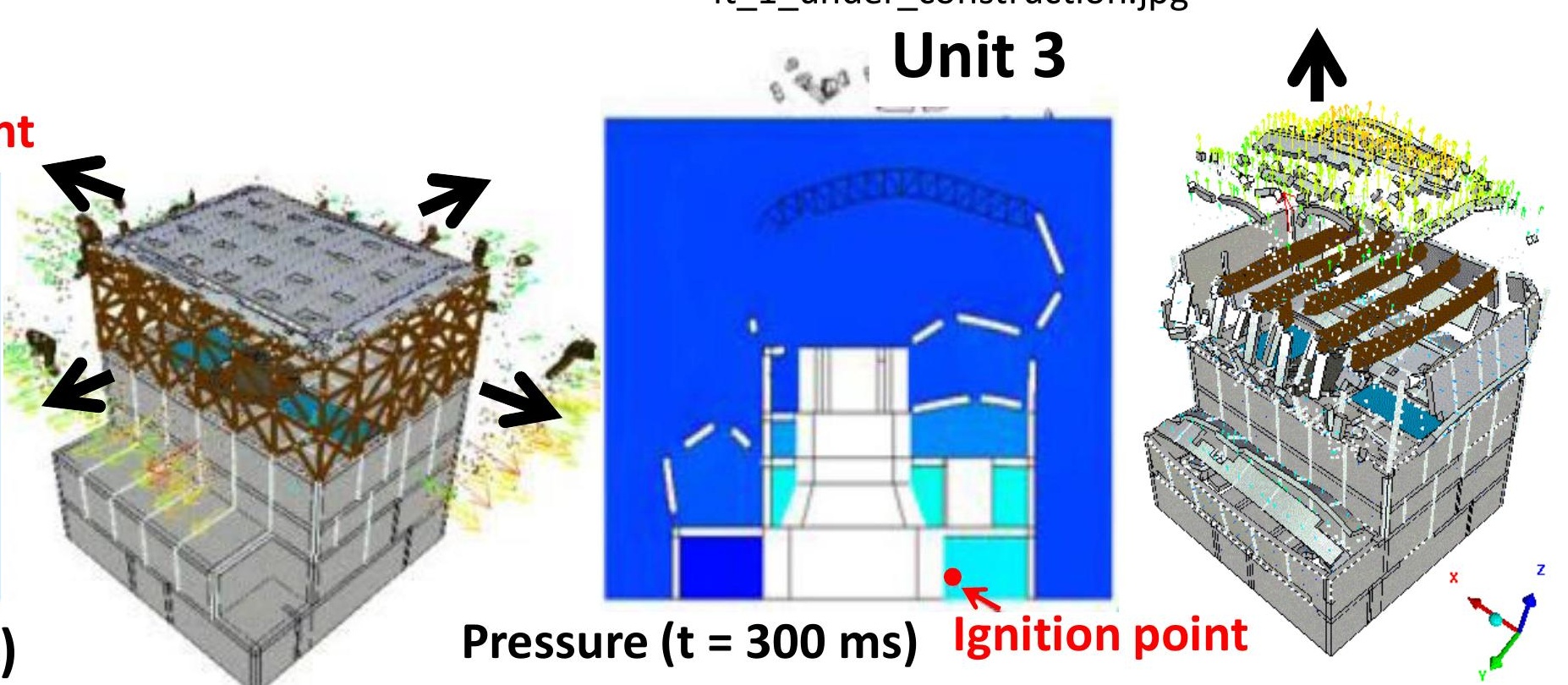


\section{Hydrogen Explosion at Unit 4}

- Hydrogen generated at Unit 3 might have been transported to Unit 4 through SGTS piping and exhaust ducts.

- The exhaust stack was shared. The valves of unit4 SGTS were open.

\section{Reactor Building of Unit 4}

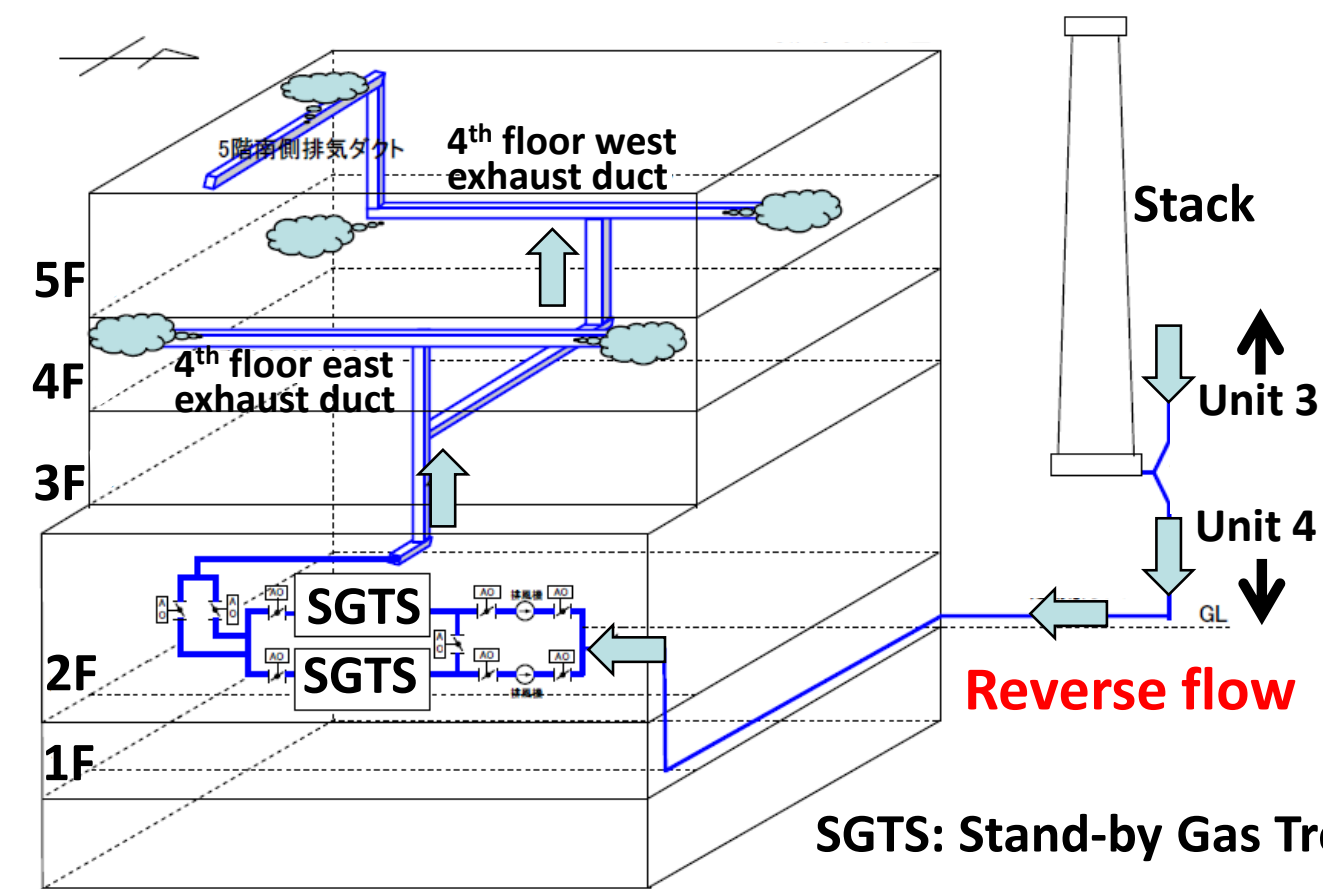

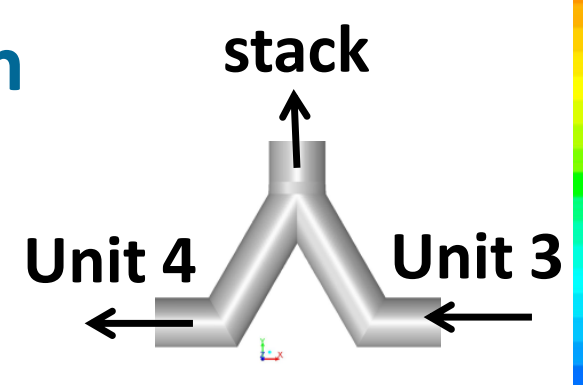

Analysis done by former JNES WWW.nsr.go.jp/archive/jnes/content/000125907.pdf

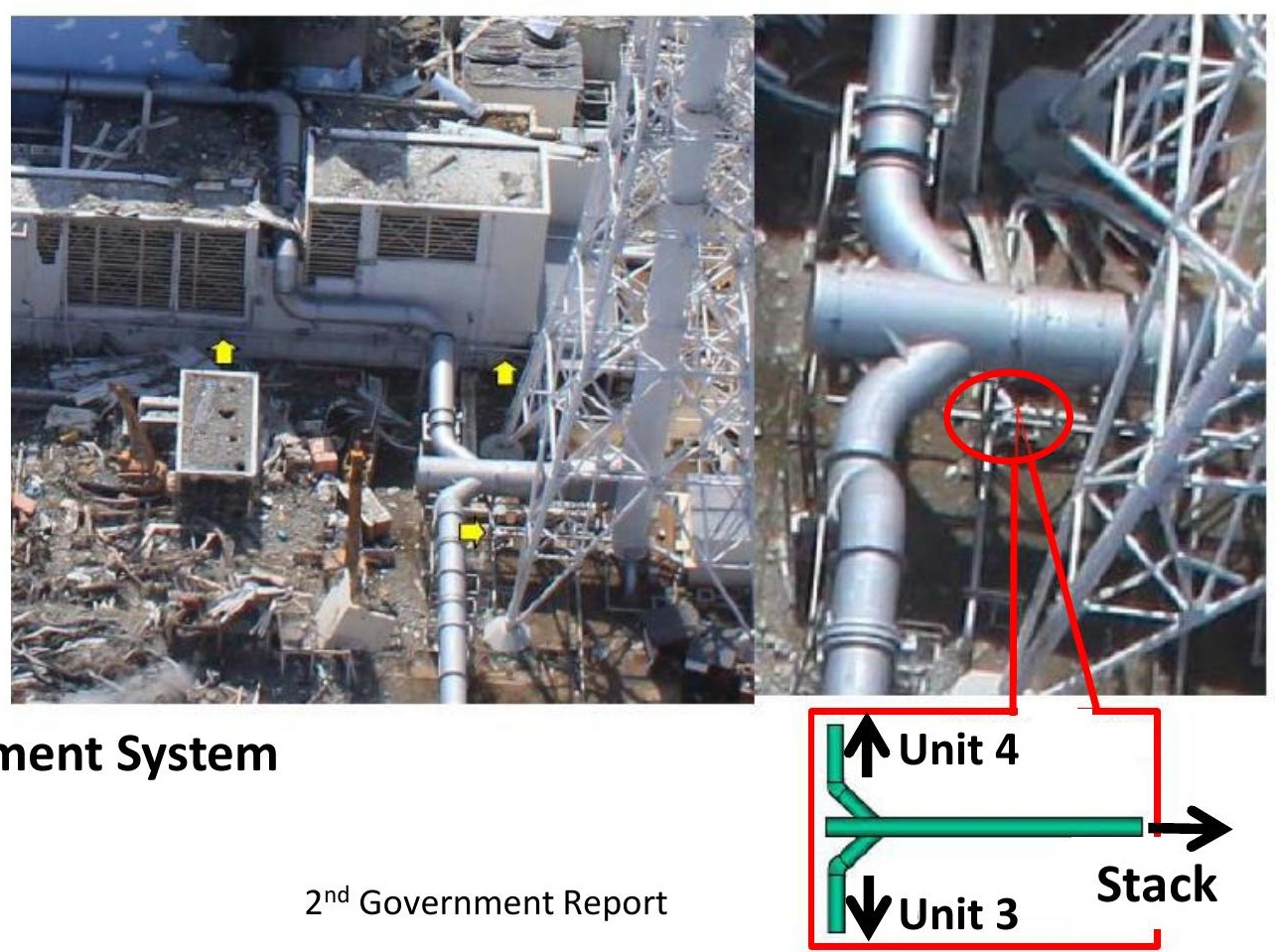




\section{End States of Units 1 to 3: OECD/NEA BSAF Project Phase I}

OECD/NEA CSNI launched the BSAF (Benchmark Study of the Accident at the Fukushima Daiichi NPP) Project in Nov. 2012.

- 16 organizations from 8 countries (France, Germany, Korea, Russia, Spain, Switzerland, the United States, and Japan) participated.

\section{Phase I Summary Report (March 2015)}

- Qualitative description of the plausible end states after comparison of the best estimate case analyses

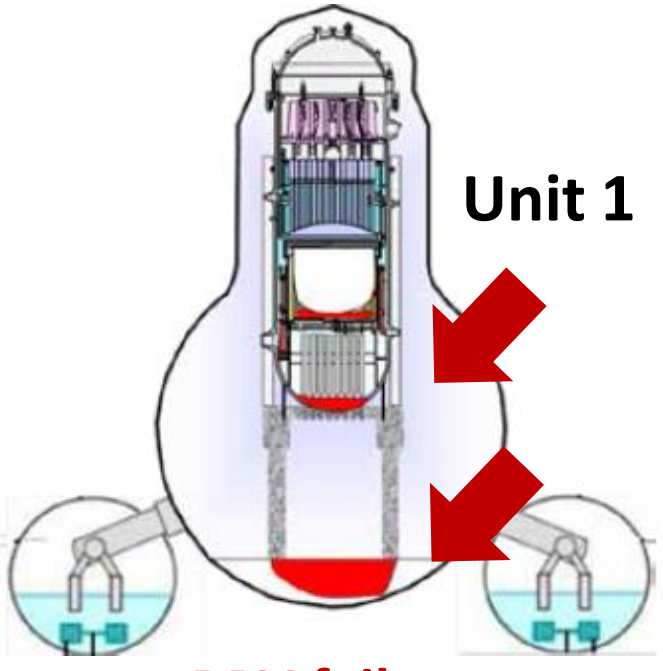

RPV failure

Every calculation predicted that extensive damage occurred.

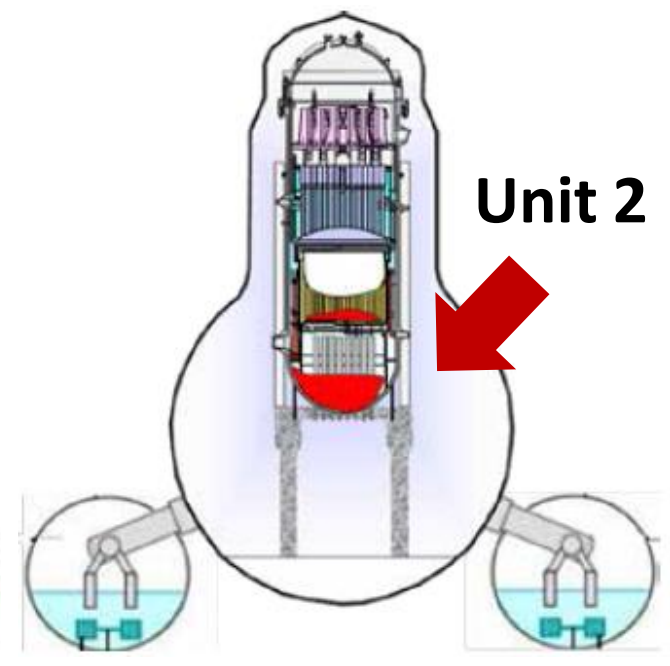

No RPV failure The majority of calculations do not predict RPV failure

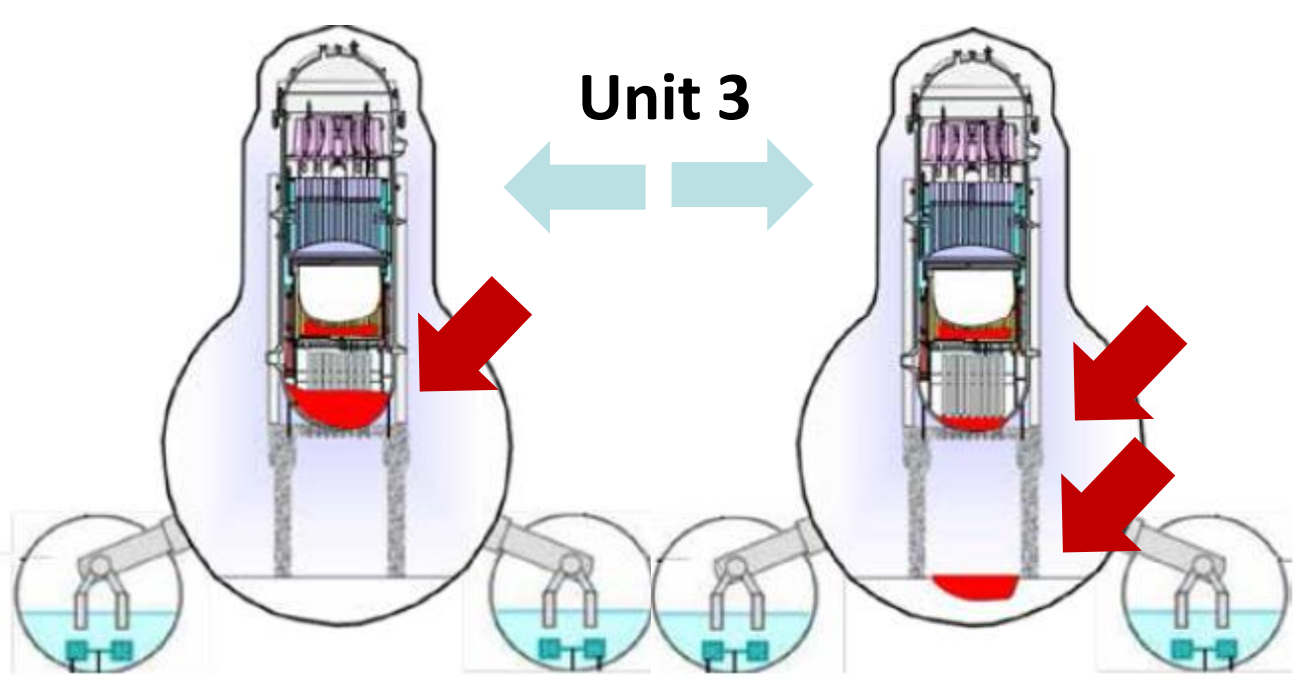

Split into two groups:

a) No RPV failure

b) RPV failure and temporary $\mathrm{MCCl}$ scenario 


\section{Source Term Evaluation}

- The IAEA collected / compared the source terms evaluated by various organizations with different methods and assumptions.

- Technical Volume 1 of the IAEA Fukushima report: "The total amount of aerosol based fission product releases from all of the Fukushima Daiichi units was about one order of magnitude smaller than that from the Chernobyl accident."

IAEA Fukushima report, Technical Volume 1/5 (2015)

Publication [14]: HOSHI, H., HIRANO, M., Severe Accident Analyses of Fukushima - Daiichi Units 1 to 3, Side event by Government of Japan at $56^{\text {th }}$ IAEA General Conference, Vienna, 2012, JNES (2012),

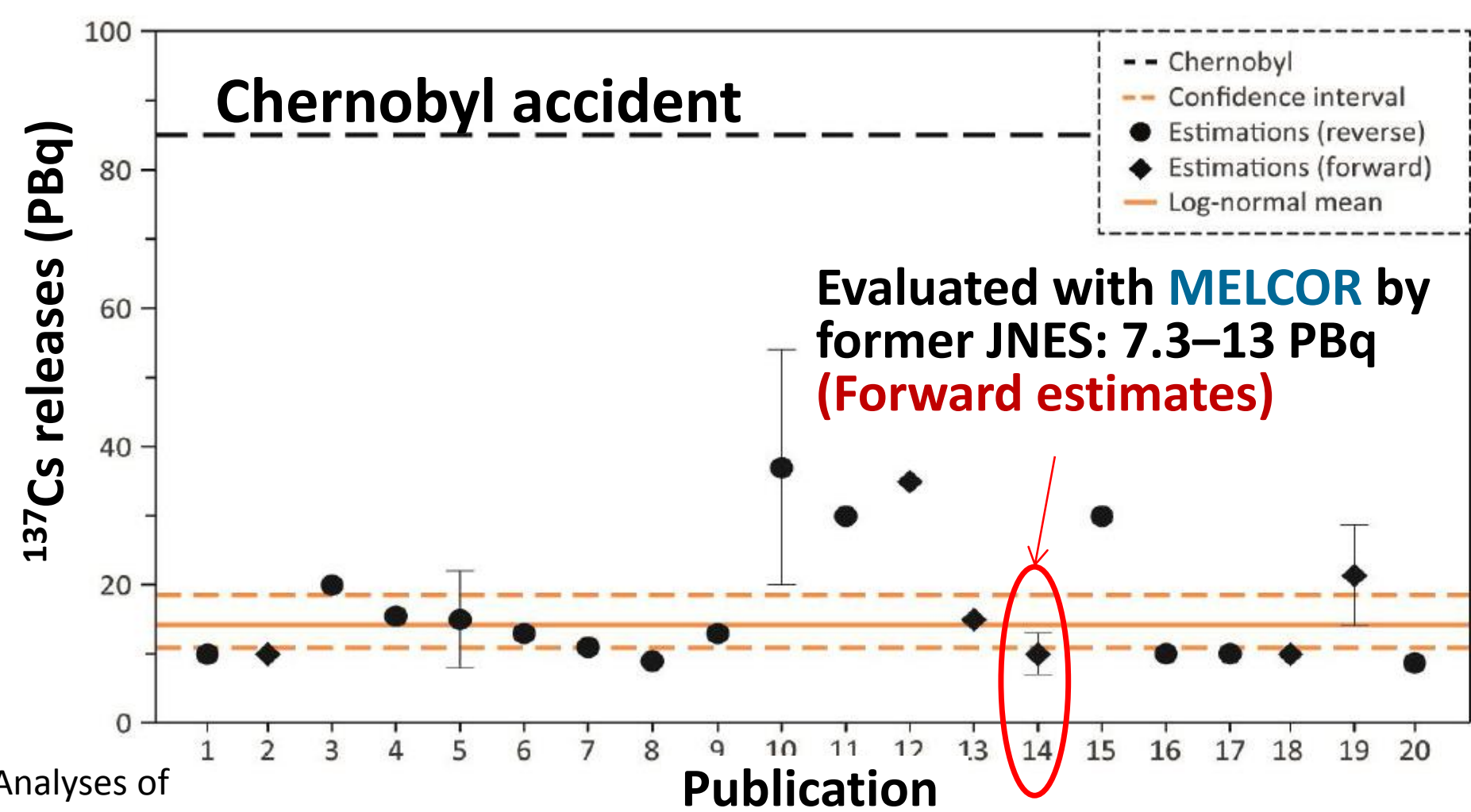

FIG. 1.4-4. Estimated atmospheric releases of 137Cs 


\section{SA Progression and Source Terms}

Hirano, Hoshi and Homma, Presented at U.S.NRC RIC, March 2013.

The former JNES has conducted a SA progression analysis with MELCOR developed by U.S.NRC. The NRA continues to do it.

- Release timings are in good agreement with the monitoring data.

- The largest peak in the morning on March 15 was probably caused by PCV failure at Unit 2

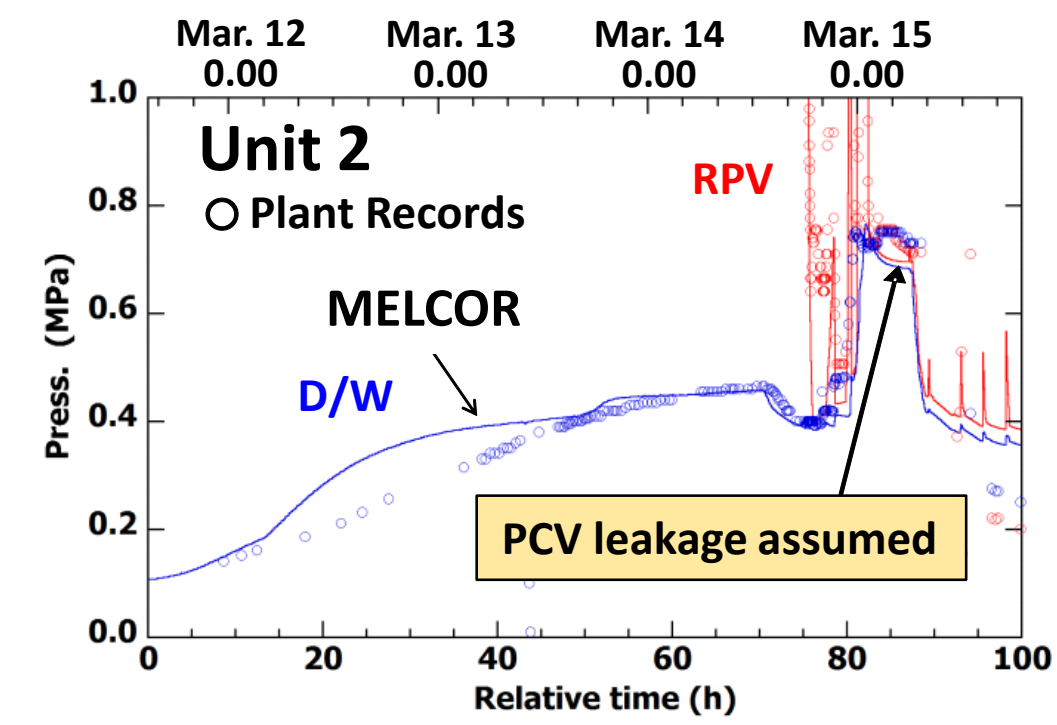

Comparison between the source terms by MELCOR and monitoring data

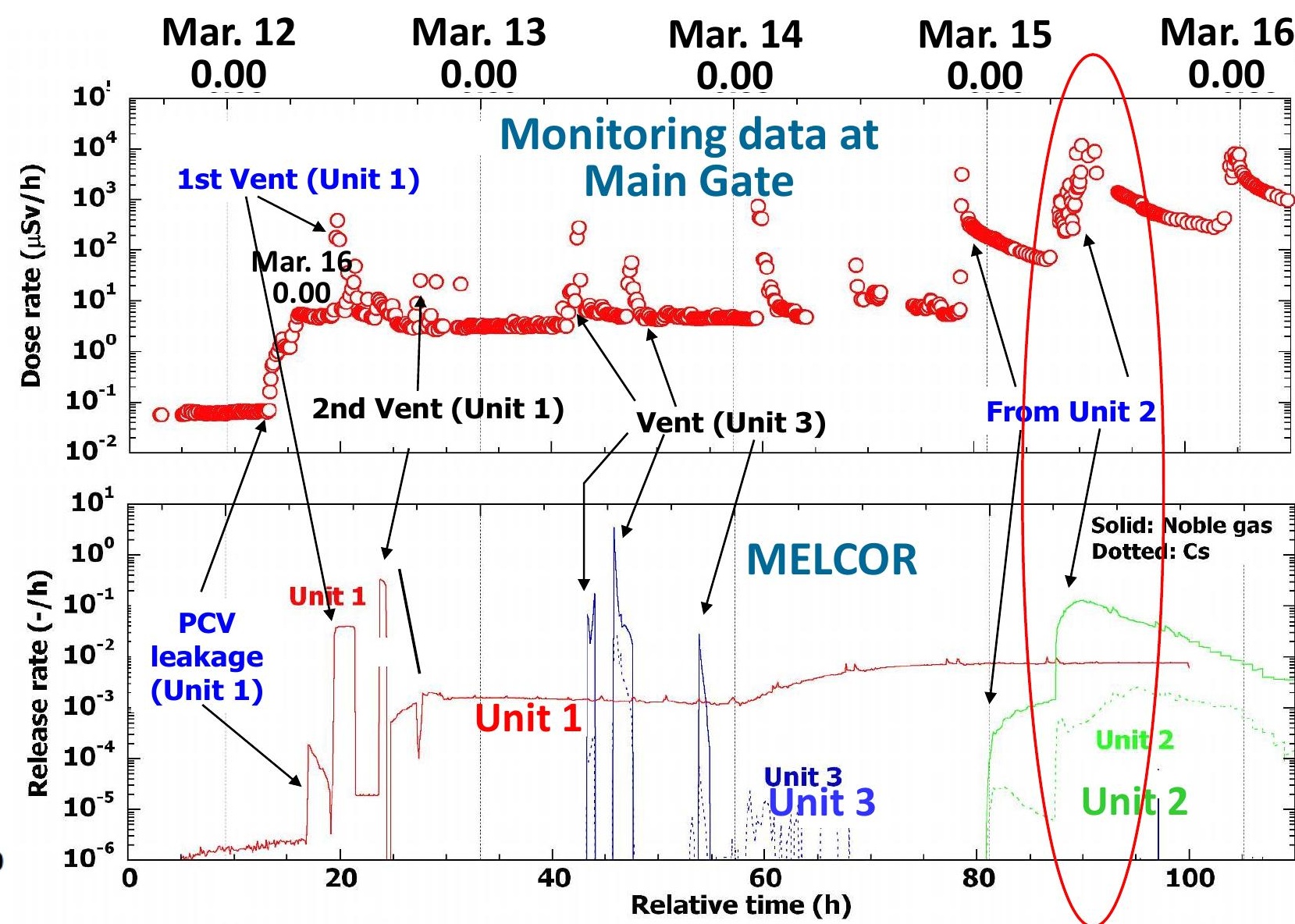


- During the accident, the SPEEDI simulation had been done every hour assuming a unit release ( $1 \mathrm{~Bq} /$ hour) since the source terms were not available. $\Rightarrow$ The results were equivalent to the meteorological data.
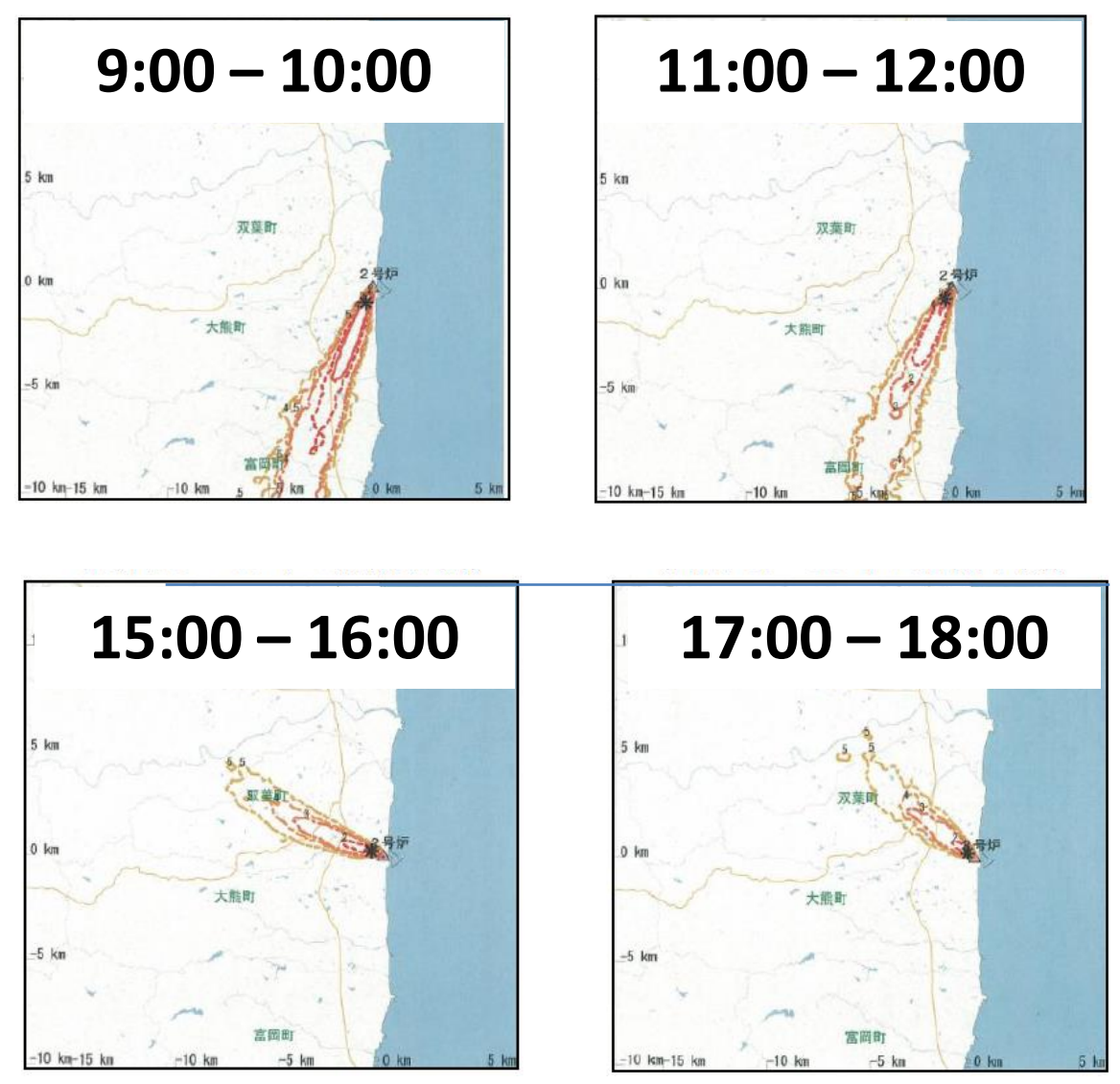

Final Report from Government's Investigation Committee (July 2012)

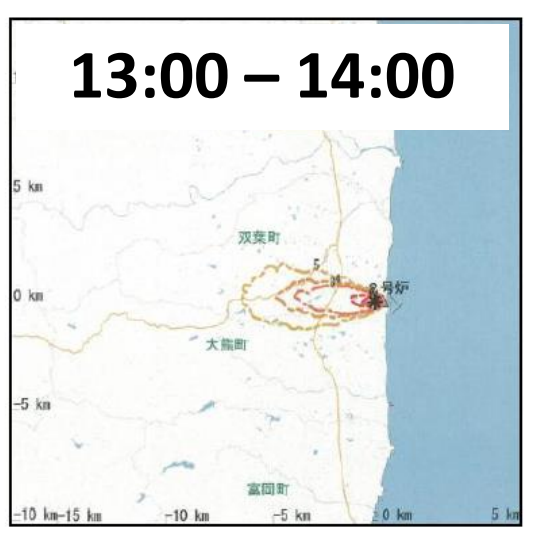

SPEEDI calculations Mar. 15, 2011

Source: M. Chino, JAEA, May 2013 Precipitation (Rainfall)

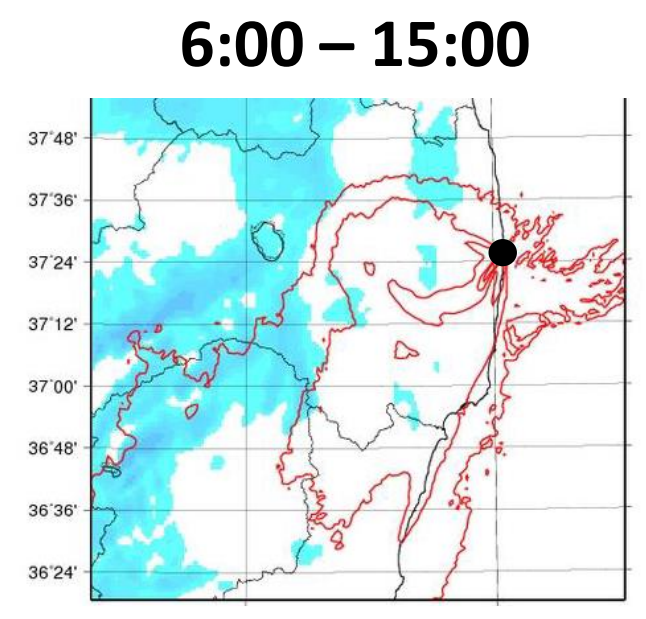
15:00-21:00

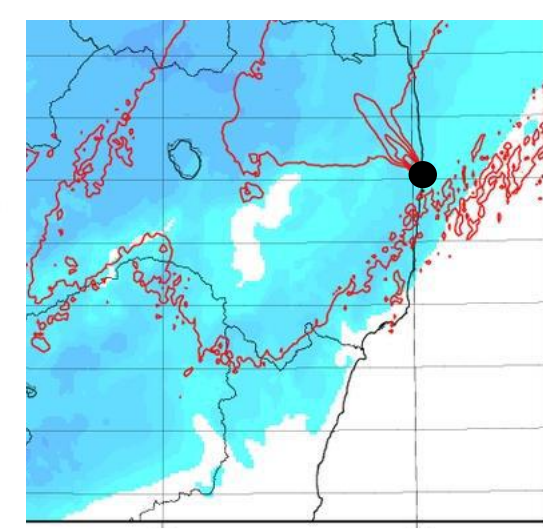

http://www.aec.go.jp/jicst/NC/iinkai/teirei/siryo2013/siryo18/siryo1.pdf 


\section{Some Lessons Learned}




\section{Lack of "Defense-in-Depth" against external hazards}

- Large scale "common cause failures (CCFs)" by external hazards should have been prevented/mitigated.

- We should have been prepared for "Low frequency, high consequence events" beyond design basis.

- Actually, the Defense-in-Depth (DiD) had not been taken into consideration for external events.

- Watertight doors were not implemented, Seawater pumps were not protected. AM measures were not effective, ...

- Training / drills assuming external events had not been conducted.

- DiD has been and will continue to be an effective way to account for uncertainties.

- Effective independence between different layers of defense

- More "diversity" and "independence" rather than "redundancy" 


\section{Lack of Agility}

Diet's Report: NAIIC : The National Diet's Fukushima Nuclear Accident Independent Investigation Commission, Reported to the Diet in July 2012

- The Seismic Design Review Guide was revised in 2006 and a requirement was newly introduced against tsunami. So-called "backcheck" was in progress, but its progress was very slow.

n "Uncertainty allows for wishful thinking" + "Safety myth"

- Lack of agility, lack of safety culture

\section{Diet Report}

- As the regulatory agency was aware of TEPCO's delaying of countermeasures, but did not follow up with any specific instructions. Nor did they properly supervise the back-check progress.

- When new findings indicate the possibility of a tsunami exceeding previous assumptions, the operator is required to quickly implement countermeasures, rather than taking time to clarify the scientific basis for that possibility through studies of sediment .... 
Seismicity Gap Area (no record of large earthquake):

- Major opinion: Majority of scientists believed the shallow plate boundary along the Japan trench was not able to store a large amount of strain (coupling is weak).

New findings / minor opinion

- In 2002, HERP* pointed out the possibility of a tsunami earthquake occurring anywhere along the Japan Trench including the gap area could not be ruled out.

- In 2008, TEPCO did hypothetical calculation assuming a M 8.2 earthquake occurring off the coast of Fukushima Pref. $\longrightarrow$ Max. $\sim 15.7 \mathrm{~m}$

- TEPCO also conducted a Jogan (869)-type tsunami

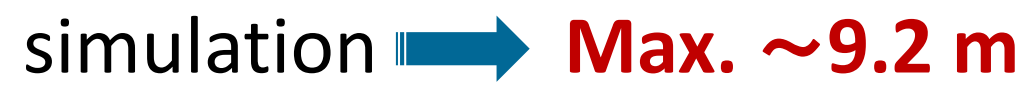

- However, TEPCO decided only on a plan to ask JSCE* for investigation such as tsunami deposit survey, rather than take any immediate measures.

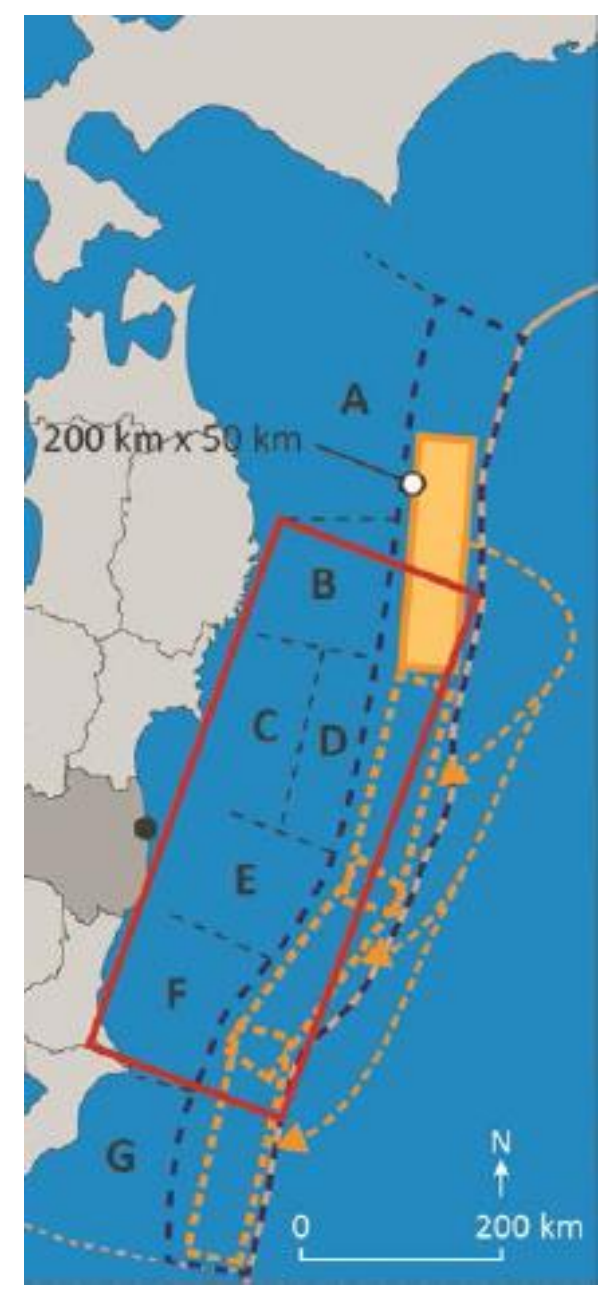




\section{"Regulatory Capture" Pointed out in the Diet's Report}

Diet's Report (July 2012)

\section{Message from Chairman}

- ... this was a disaster "Made in Japan." Its fundamental causes are to be found in the ... Japanese culture: our reflexive obedience; our reluctance to question authority; ... and our insularity.

\section{Organizational issues ...}

- ... actual relationship lacked independence and transparency, ... In fact, it was a typical example of "regulatory capture," ...

\section{Lack of expertise}

-... the two incorporated technical agencies advising NISA, namely, JNES and JAEA, have been too rigidly tied to NISA ....

\section{Conclusions}

- ... The lack of expertise resulted in "regulatory capture,"... They avoided their direct responsibilities by letting operators apply regulations on a voluntary basis. 


\section{"Myth of Safety" Pointed Out in the Government's Report}

\section{"Myth of Safety"}

- ... a fundamental problem of the inability to capture such crises as a reality that could happen in our lives; this, in turn, is the result of a myth of safety that existed among nuclear operators including TEPCO as well as the government, that serious severe accidents could never occur in NPPs in Japan.

\section{"Basic Assumption" in the IAEA DG Report}

- Because of the basic assumption that NPPs in Japan were safe, there was a tendency for organizations and their staff not to challenge the level of safety.

- The reinforced basic assumption among the stakeholders about the robustness of the technical design of NPPs resulted in a situation where safety improvements were not introduced promptly. 
"Complacency" together with "Bureaucracy" allowed "Safety myth" to prevail, having let "Continuous improvement" cease.

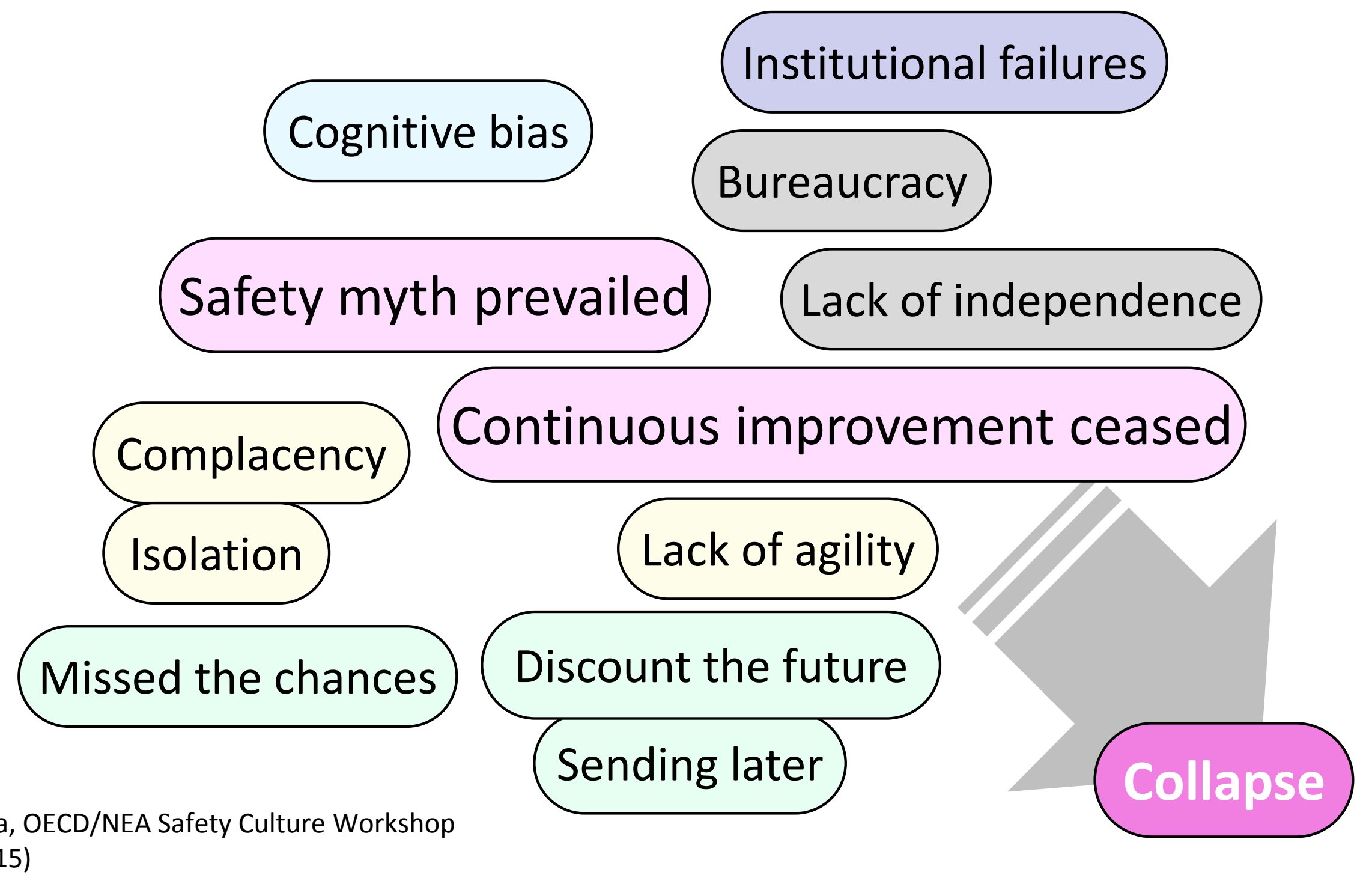




\section{Safety Enhancements}




\section{NRA: Nuclear Regulation Authority}

Established in Sept. 2012

\section{- Independence}

Nuclear regulation and nuclear promotion were clearly separated, and the NRA was established as an independent commission body defined by law* affiliated with MOE (Minister of Environment).

* a council-system organization based on Article 3 of the National Government Organization Act, ensuring its independence without any control or supervision by other organizations.

- Integrated

Nuclear regulation functions regarding safety, security, safeguards, radiation monitoring and radioisotopes were integrated into the NRA.

T. Fuketa, NRA, presented at U.S.NRC RIC2013, March 13, 2013: http://www.nsr.go.jp/data/000067048.pdf
Integrated and Independent
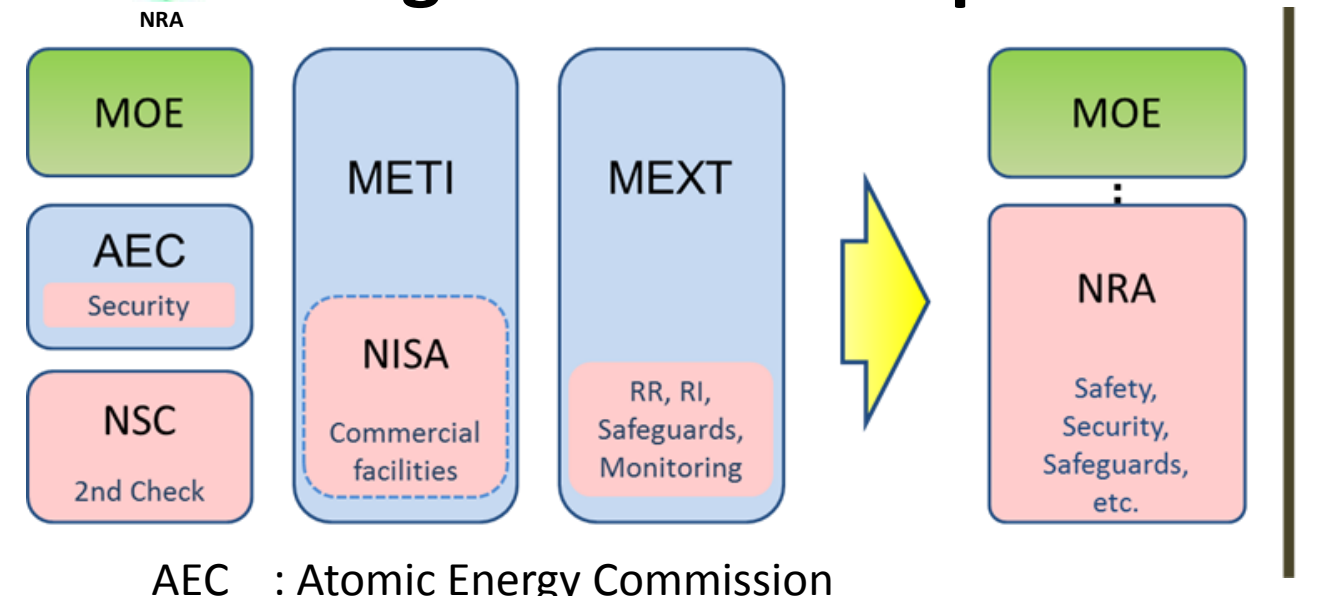

AEC

METI

MEXT

AEC : Atomic Energy Commission

METI : Ministry of Economy, Trade and Industry

MEXT: Ministry of Education, Culture, Sports, Science and Technology

MOE : Ministry of the Environment

NISA : Nuclear and Industrial Safety Agency (abolished)

NSC : Nuclear Safety Commission (abolished) 
Requirements for B-DBA

- DEC: Design extension conditions defined in IAEA SSR-2/1

\begin{tabular}{|c|c|c|}
\hline & Speci \\
\hline & \multirow{2}{*}{$\begin{array}{l}4^{\text {th }} \text { Layer } \\
\text { of DiD }\end{array}$} & Prevention of $\mathrm{CV}$ failure \\
\hline & & Prevention of core damage \\
\hline$<$ Pre-existed $>$ & \multirow{7}{*}{$\begin{array}{l}3^{\text {rd }} \text { Layer } \\
\text { of DiD }\end{array}$} & Natural phenomena \\
\hline Natural phenomena & & Fire \\
\hline Fire & & Reliability \\
\hline Reliability & & Reliability of power supply \\
\hline Reliability of power supply & & Ultimate heat sink \\
\hline Ultimate heat sink & & Function of other SCCs \\
\hline Function of other SCCs & & \\
\hline Seismic/Tsunami resistance & & Seismic/Tsunami resistance \\
\hline
\end{tabular}

$<$ New $>$

Suppression of radioactive materials dispersal

Specialized Safety Facility

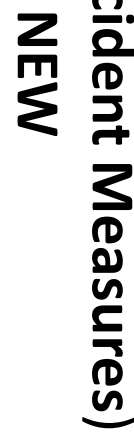

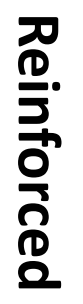

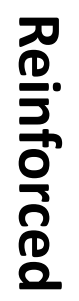




\section{New Regulatory Requirements: Enhanced Measures against Tsunami}

http://www.nsr.go.jp/data/000067048.pdf

More Stringent Standards on Tsunami
It is required to define "design basis tsunami" that exceeds the largest in the historical records and to take protective measures such as breakwater wall based on it.

SSCs for tsunami protective measures are

Enlarged Application of Higher Seismic Resistance classified as Class S equivalent to RPV etc.

of seismic design importance classification.

\section{Example of protective measures against tsunami (multiple measures)}

- Breakwater wall for prevention of inundation to the site

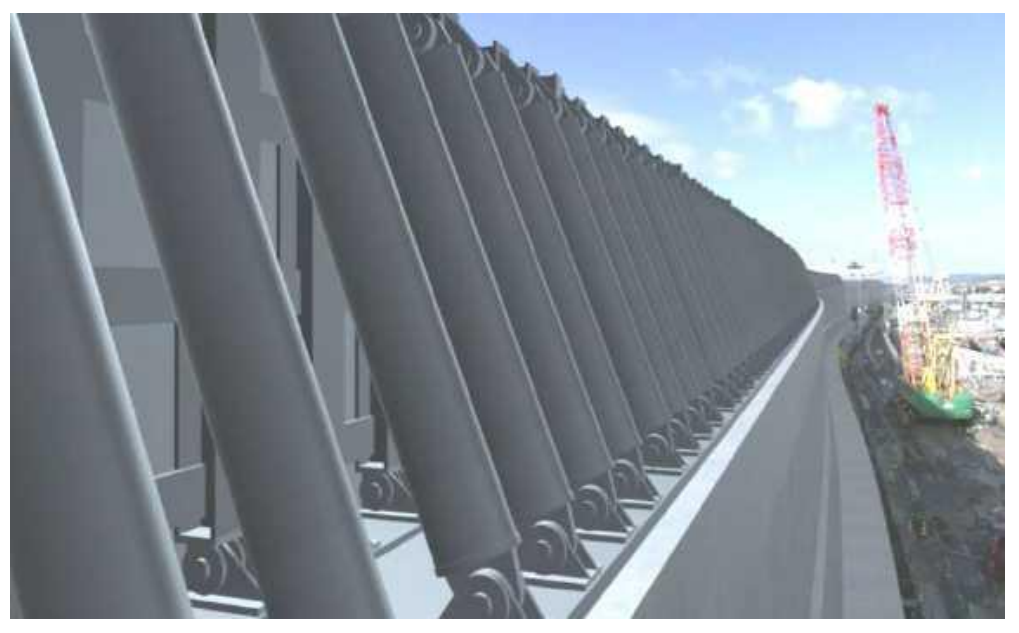

- Tsunami gate for prevention of water penetration into the building

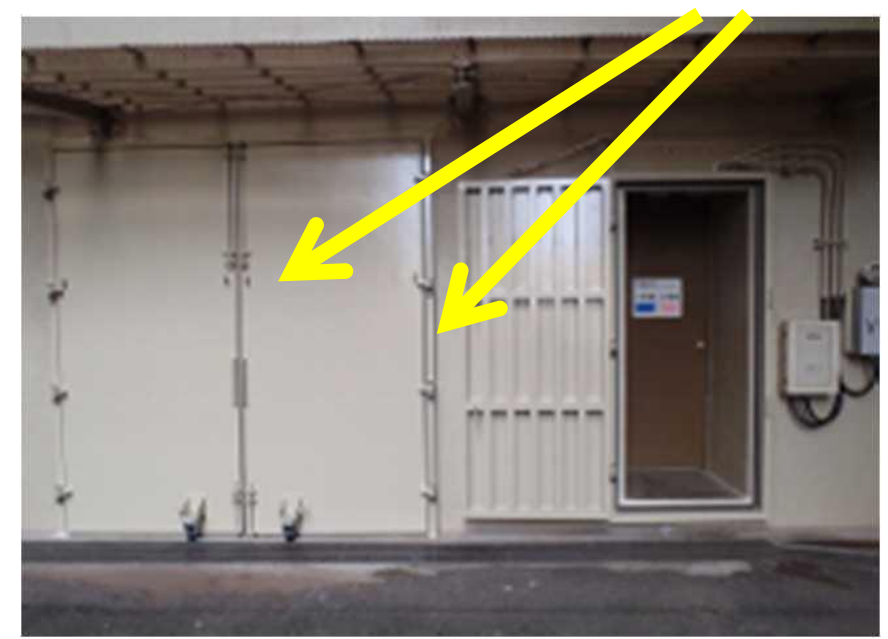




\section{Measures against Intentional Aircraft Crash, etc.}

http://www.nsr.go.jp/data/000067048.pdf

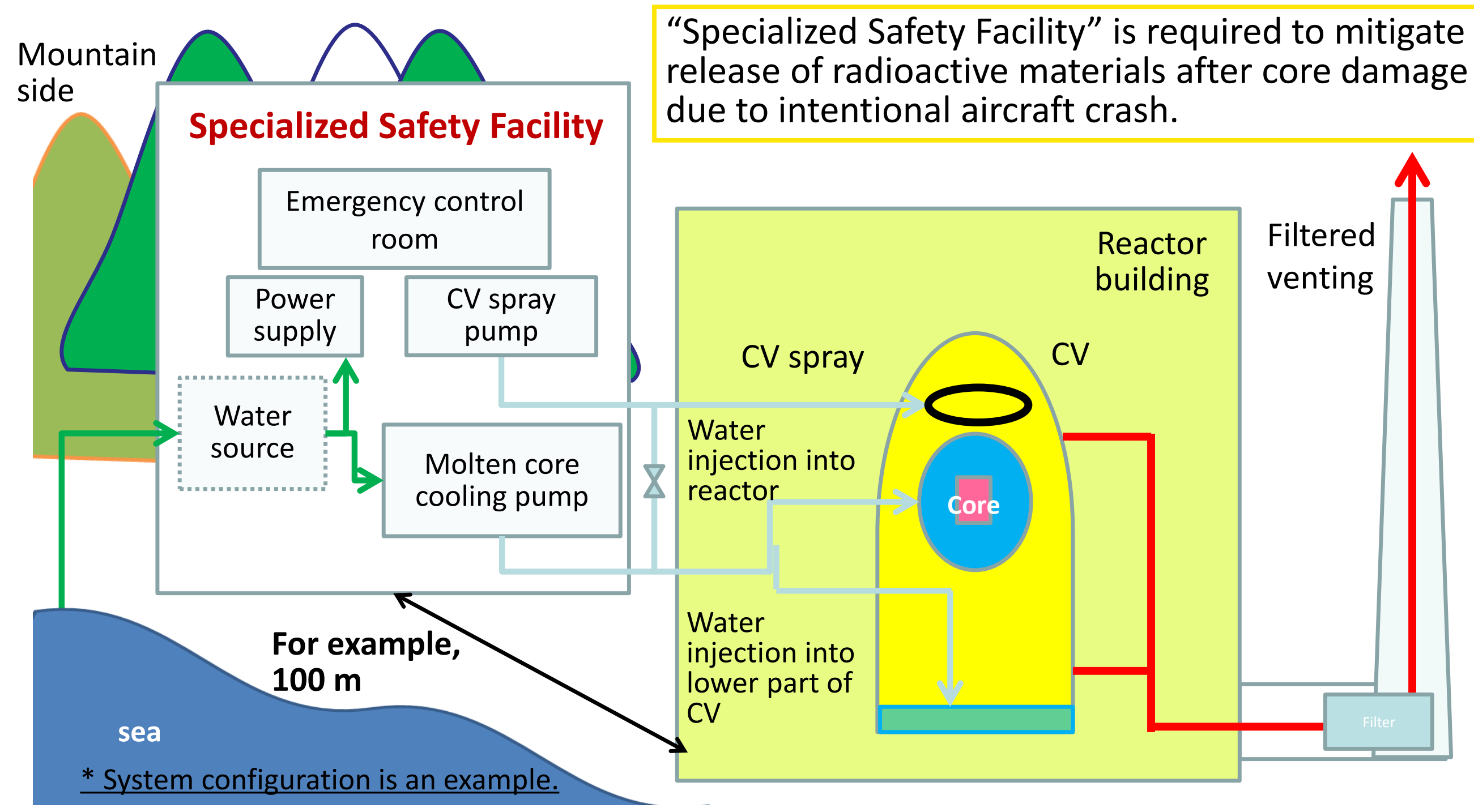

For BWR, one filtered venting for prevention of containmehit failure and another filtered venting of Specialized Safety Facility are acceptable solution. 
Issued on May 27, 2015

- NRA's Mission Statements

$$
\text { The NRA's Core Values and Principles }
$$

The Statement of Nuclear Safety Culture

\begin{tabular}{|c|} 
The NRA's Core Values and Principles \\
\begin{tabular}{|c|}
\hline The Statement of \\
Nuclear Safety Culture
\end{tabular} \\
\hline
\end{tabular} $\begin{aligned} & \text { The Code of Conduct } \\
& \text { on Nuclear Security }\end{aligned}$

T. Fuketa, OECD/NEA Safety Culture Workshop (June 2015)

- Eight Traits of Nuclear Safety Culture in NRA's Statement

1. Priority to Safety $\Rightarrow$ Break with "safety myth"

2. Decision-making prioritized by safety

3. Fostering, sustaining and strengthening safety culture

4. Learning organization $\Rightarrow$ Seek out "opportunities for improvement"

5. Communication $\Rightarrow$ Get rid of "isolation"/"self-righteousness"

6. Questioning attitude $\Rightarrow$ Avoid "complacency"

7. Rigorous and prudent judgment and action with agility

8. Harmonization with nuclear security 
- One of the most important lessons learned is "Lack of Defense-in-Depth against external hazards". We need to continuously enhance DiD since DiD has been and will continue to be an effective way to account for uncertainties.

- We need to keep reminding that "Complacency" together with "Bureaucracy" allowed "Safety myth" to prevail, having let "Continuous improvement" cease.

- Commissioner Fuketa of NRA stated in the OECD/NEA SC Workshop*:

- We, however, acknowledge we are oblivious. Numerous sprouts of safety myth reappear already.

- We must incorporate lessons-learned into the "institutional memory" of the NRA. We must create an environment where a gene letting us think "safety first" can survive. 


\section{References}

- $\quad 1^{\text {st }}$ Government Report (June 2011): Report of the Japanese Government to the IAEA Ministerial Conference on Nuclear Safety, Nuclear Emergency Response Headquarters, Government of Japan, June 2011

- $2^{\text {nd }}$ Government Report (September 2011): Additional Report of the Japanese Government to the IAEA (Second Report), Nuclear Emergency Response Headquarters, Government of Japan, September 2011

- Diet's Report (July 2012): The Official Report of the Fukushima Nuclear Accident Independent Investigation Commission (NAIIC), the National Diet of Japan, 2012

- Interim Report from Government's Investigation Committee (Dec. 2011): Interim Report, Investigation Committee on the Accident at Fukushima NPS of TEPCO, Dec. 26, 2011

- Final Report from Government's Investigation Committee (July 2012): Final report, Investigation Committee on the Accident at Fukushima NPS of TEPCO, July 23, 2012

- IAEA DG Report and Technical Volumes 1 to 5 (2015): The Fukushima Daiichi Accident, Report by the Director General and Technical Volumes 1 to 5 (2015)

- T. Fuketa, OECD/NEA Safety Culture Workshop (June 2015): OECD NEA/CNRA/ CSNI/CRPPH Joint Workshop on Challenges and Enhancements to Safety Culture of the Regulatory Body, Paris, June 3, 2015

- Y. Shimizu, IAEA Effective Nuclear Regulatory Systems (April 2016): Y. Shimizu, "Lessons Learned from the Fukushima Daiichi Accident, Actions Taken and Challenges Ahead," presented at IAEA International Conference on Effective Nuclear Regulatory Systems, Vienna, Austria, April 11-15, 2016 


\section{Appendix}

Key: It was difficult to open Air-Operated Valves (AOVs)

- For seawater injection by fire engines, it was necessary to depressurize RPV by opening SRVs. It was needed to open AOVs in the venting system to prevent PCV failure.

- AOVs need:

- DC power to open the pilot valve (solenoid valve) Car batteries

- Compressed air $\|$ Mobile compressor, nitrogen gas cylinders

- Mobile

Instrument Air (IA) system compressors

- Nitrogen gas cylinders

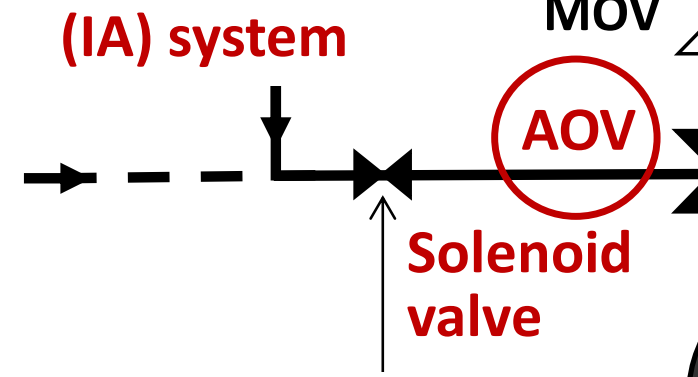

Car battery

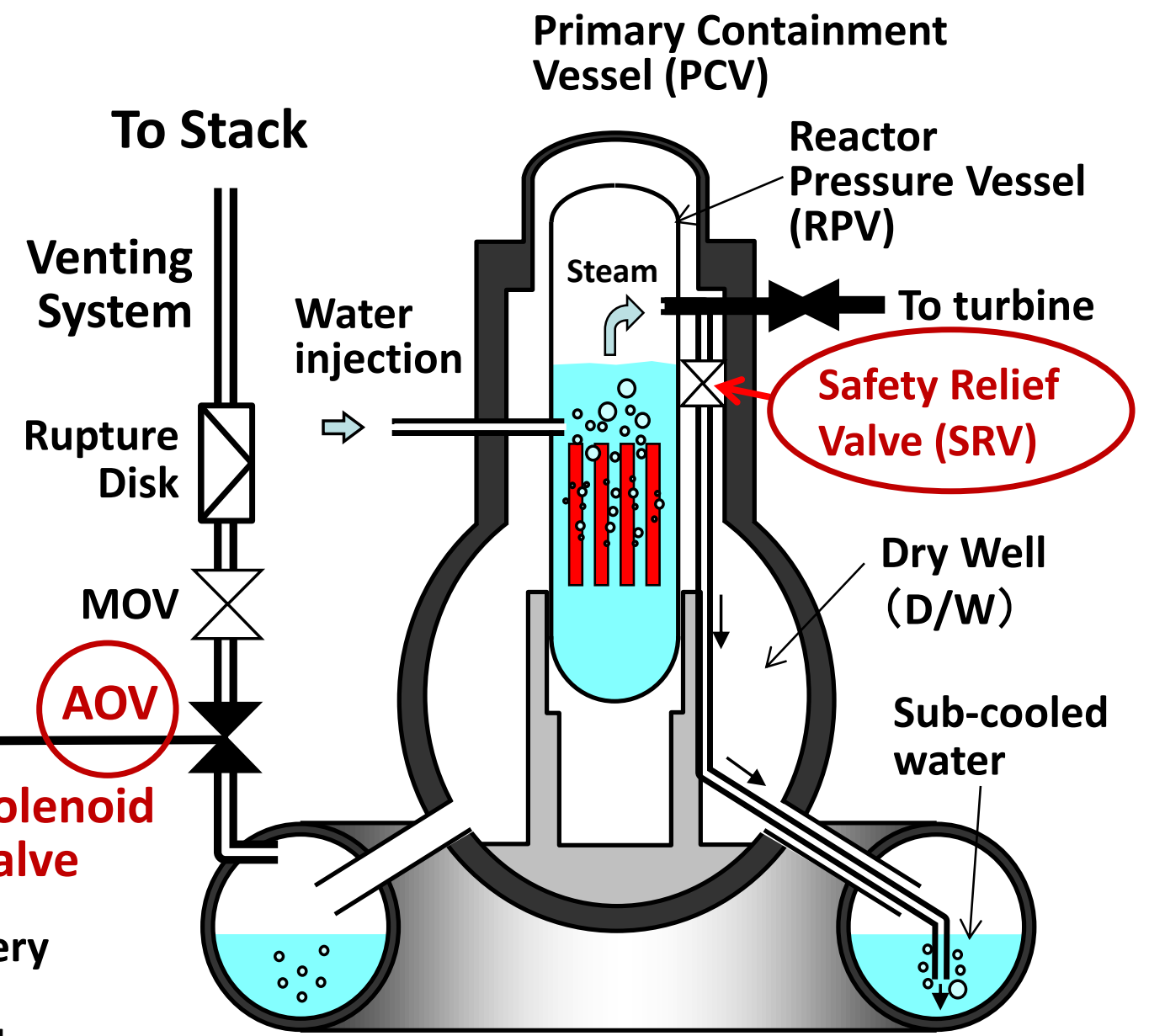

https://upload.wikimedia.org/wikipedia/commons/2/25/Mark_I_ Containment.jpg

Suppression Pool (S/C) or Wet Well (W/W) 


\section{Example of Use of Mobile Equipment: Measures against Station Blackout (SBO)}

$\checkmark$ Install both mobile alternate power sources (power vehicle, batteries, etc.) and permanent alternate AC power sources.

- Batteries for 8 hours without load shedding +16 hours with load shedding

- Alternate onsite AC power supply for 7 days

- External support from offsite by the 6th day

- Alternative MC, PC, MCC

$\checkmark$ It is also required to install the third station battery system.

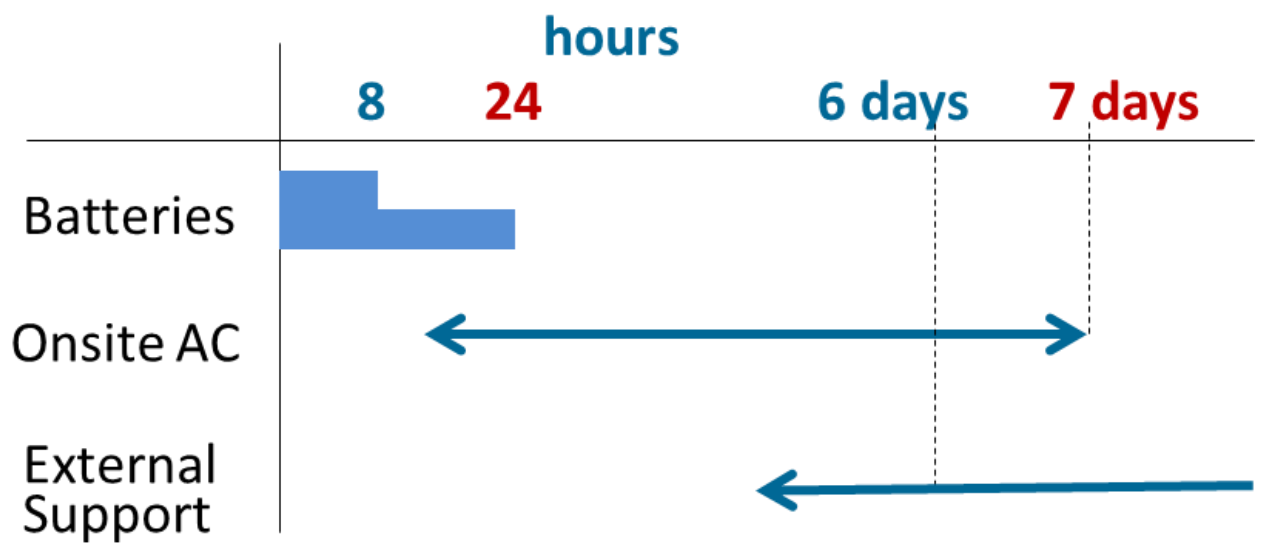

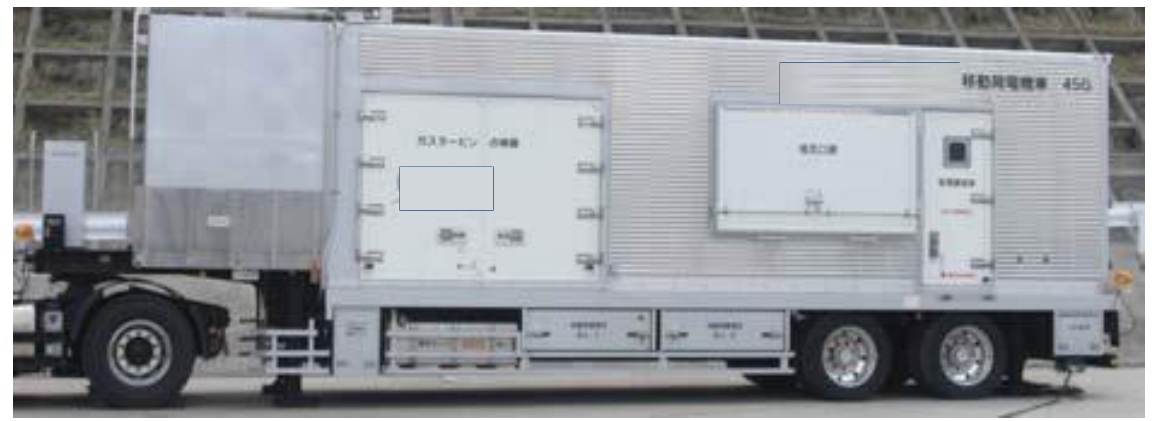

Alternative onsite AC power (Power Vehicle) 